\title{
Mineralocorticoid receptor antagonists and kidney diseases: pathophysiological basis
}

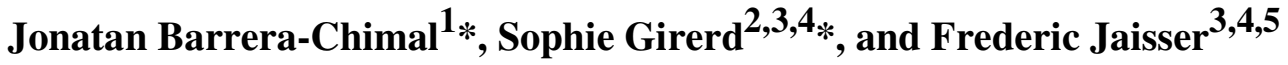

${ }^{1}$ Laboratorio de Fisiología Cardiovascular y Trasplante Renal, Unidad de Medicina Traslacional, Instituto de Investigaciones Biomédicas, Universidad Nacional Autónoma de México and Instituto Nacional de Cardiología Ignacio Chávez, Mexico City, Mexico.

${ }^{2}$ Transplant Unit, Nephrology Department, Nancy University Hospital, Lorraine University, Vandoeuvre-lès-Nancy, France.

${ }^{3}$ INSERM U1116, Clinical Investigation Centre, Lorraine University, Vandoeuvre-lèsNancy, France.

${ }^{4}$ INI-CRCT (Cardiovascular and Renal Clinical Trialists) F-CRIN Network, Nancy, France.

${ }^{5}$ INSERM, UMRS 1138, Team 1, Centre de Recherche des Cordeliers, Sorbonne University, Paris Descartes University, Paris, France.

*These authors contributed equally to this work.

Running title: MR antagonists and kidney disease

Word count: 8283

Key words: aldosterone, fibrosis, kidney injury, inflammation, clinical study

\section{Corresponding author:}

Dr. Frédéric Jaisser

INSERM U1138, Centre de Recherche de Cordeliers, Team 1

15 rue de l'Ecole de Médecine, 75006, Paris, France

Tel: +33144278106

E-mail: frederic.jaisser@inserm.fr 


\begin{abstract}
Chronic kidney disease (CKD) represent a global health concern, and its prevalence is increasing. The ultimate therapeutic option for CKD is kidney transplantation. However, the use of drugs that target specific pathways to delay or halt CKD progression such as ACEis, ARBs and SGLT-2 inhibitors is limited in the clinical practice. Mineralocorticoid receptor (MR) activation in non-classical tissues, such as the endothelium, smooth muscle cells, inflammatory cells, podocytes, and fibroblasts may have deleterious effects on kidney structure and function. Several pre-clinical studies have shown that mineralocorticoid receptor antagonists (MRAs) ameliorate or cure kidney injury and dysfunction in different models of kidney disease. In this review, we will present the pre-clinical evidence showing a benefit of MRAs in acute kidney injury (AKI), the AKI to CKD transition, hypertensive and diabetic nephropathy, glomerulonephritis, and kidney toxicity induced by calcineurin inhibitors. We also discuss the molecular mechanisms responsible for renoprotection related to MRAs that lead to reduced oxidative stress, inflammation, fibrosis, and hemodynamic alterations. The available clinical data support a benefit of MRA in reducing proteinuria in diabetic kidney disease and improving cardiovascular outcomes in CKD patients. Moreover, a benefit of MRAs in kidney transplantation has also been observed. The past and present clinical trials describing the effect of MRAs against kidney injury are presented and the risk of hyperkalemia and options, such as potassium binding agents or non-steroidal MRAs, are also addressed. Altogether, the available pre-clinical and clinical data support a benefit of MRA in CKD which has to be further explored in future clinical trials.
\end{abstract}




\section{Introduction}

The classic effect of aldosterone is exerted in the epithelium of the aldosteronesensitive distal nephron (ASDN), where it binds to the mineralocorticoid receptor (MR) and controls sodium reabsorption and potassium secretion. In these cells, specificity is conferred by the expression of $11 \beta$-hydroxysteroid dehydrogenase type 2 (11ß-HSD2). ${ }^{1}$ MR expression has been detected in non-classical tissues, where its activation may be pathophysiological. MR activation in non-classical tissues is not always due to the action of aldosterone, as $11 \beta$-HSD2 is not always expressed. ${ }^{1}$ Table 1 summarizes the cell types in the kidney in which MR and/or 11 $\beta$-HSD2 are expressed and whether MR-activation effects are observed. MR expression may be upregulated in some pathological conditions, such as diabetes ${ }^{2}$, heavy proteinuria ${ }^{3}$, vascular ageing ${ }^{4}$ and hypertension ${ }^{5}$, thus amplifying MR signaling.

Steroidal mineralocorticoid receptor antagonists (MRAs) such as spironolactone or eplerenone have been used for decades as diuretics drugs for the management of hypertension, primary aldosteronism and heart failure. Canrenone is the active metabolite of spironolactone and is available in some countries. An injectable preparation of potassium canrenoate is also available in some countries. More recently, novel non-steroidal MRAs with improved safety profile have been developed including, BR-4628 (Bayer), finerenone $\begin{array}{llllll}\text { (Bayer), PF-03882845 } & \text { (Pfizer), } & \text { SM-368229 } & \text { (Dainippon } & \text { Sumitomo), AZD9977 }\end{array}$ (AstraZeneca) among others. None of them is currently marketed. ${ }^{1,6,7}$

\section{Pre-clinical data that support a benefit of MR antagonists (MRAs) in kidney diseases Pre-clinical data: Benefit of MRAs on acute kidney injury (AKI) induced by ischemia/reperfusion (IR)}


Several clinical conditions can lead to a reduction in blood supply to the kidney, resulting in AKI. Indeed, a major cause of AKI is renal IR. In the clinical setting, there is no pharmacological approach to treat this condition. In 2007, Mejía-Vilet et al. showed that prophylactic MR antagonism with spironolactone efficiently prevents acute kidney dysfunction and tubular injury induced by bilateral renal IR injury in the rat. ${ }^{8}$ The sustained reduction in renal blood flow observed in IR-untreated rats was prevented in the spironolactone treated groups and was accompanied by a reduction in oxidative stress and increased activation of endothelial nitric oxide synthase (eNOS). ${ }^{8}$ Adrenal gland removal had similar protective effects against ischemic injury. ${ }^{9}$ In common clinical situations, ischemic AKI cannot be anticipated. Thus, it was further shown that spironolactone administration at the time of ischemia and even after three hours of reperfusion is fully protective, whereas the protection was only partial when spironolactone was administered six hours after ischemia induction. ${ }^{10}$ The non-steroidal MR antagonists (MRAs) BR-4628 and finerenone have also shown beneficial effects in rat and mouse models of ischemic AKI. ${ }^{11,12}$ It was demonstrated that the benefit of MR antagonism in kidney IR is dependent on endothelin-B receptor signaling and that a sulfenic acid modification that functionally inactivates this receptor is responsible for reduced eNOS activation and therefore sustained vasoconstriction after IR. ${ }^{11,12}$ Cell-specific MR knockout mice in which MR expression in endothelial and smooth muscle cells (SMC) was targeted were developed to delineate the role of vascular MRs in renal IR injury. MR deficiency in endothelial cells had no effect on the severity of AKI. However, SMC-specific MR gene deletion prevented renal dysfunction and structural injury induced by IR. ${ }^{13}$ This protective effect was related to reduced Rac1induced oxidative stress in SMCs, thus preventing the sulfenic acid modification of the endothelin-B (ETB) receptor, leading to inefficient ETB receptor signaling and defective 
eNOS activation. ${ }^{13}$ Therefore, the SMC MR signaling pathway could potentially be specifically targeted to prevent the acute consequences of an ischemic kidney episode.

The benefit of MRAs in ischemic AKI was translated into the White Large Pig preclinical model in which MR antagonism with Soludactone ${ }^{\circledR}$ (potassium Canrenoate, a soluble MRA used in the clinic, mainly in intensive care units) prevented the effects of AKI, as shown by reduced urinary NGAL, Kim-1, and oxidative stress levels, as well as the remarkable preservation of kidney function and structure. ${ }^{13}$

The benefit of MRAs in ischemic diseases is not limited to the kidney, as the protective effects of MRAs have also been described in intestinal, cardiac, and brain ischemic injury. ${ }^{1,14,15,16}$

\section{Pre-clinical data: MR antagonism prevents the AKI to CKD transition}

Clinical and experimental studies have demonstrated that AKI is independently associated with an increased risk of CKD. Comprehensive research has targeted the mechanisms of the AKI to CKD transition, but no therapeutic options are yet available in the clinical setting. ${ }^{17}$ In 2013, Barrera-Chimal et al. showed, that a single episode of ischemic AKI can induce CKD in rats subjected to bilateral kidney IR and followed up to nine months, characterized by proteinuria, kidney dysfunction, and severe structural injury. Prophylactic spironolactone administration prevented all these alterations. ${ }^{18}$ The protective effect of spironolactone was also observed when administered in one dose up to 1.5 hours after ischemia induction or when the administration was started 24 hours after the AKI episode. ${ }^{18,19}$ MR antagonism was also able to prevent CKD induced by a short ischemic period $(20 \mathrm{~min})$ even when administered three hours after IR. ${ }^{20}$ The benefit of the nonsteroidal MRA finerenone in this setting was also demonstrated in both rat and mouse 
models of the AKI to CKD transition. ${ }^{12,19}$ Inflammatory cells play a crucial role for efficient repair after an ischemic episode. We therefore explored the impact of MRAs and targeted deletion of MRs in myeloid cells in inflammation and the development of CKD after AKI. Mice treated with finerenone or those with myeloid-specific MR deletion were protected against the AKI to $\mathrm{CKD}$ transition. This was due to a reduction of proinflammatory macrophage infiltration and the promotion of macrophage polarization to an M2-wound-healing phenotype in the acute phase after the ischemic injury. MR inhibition promoted M2 macrophage polarization by increasing macrophage interleukin-4 receptor expression and activation. ${ }^{19}$ Importantly, for translation to the clinic, Soludactone ${ }^{\circledR}$ administration in the White Large Pig model, from two days before and up to two days after the ischemic insult, was also able to prevent AKI-induced CKD progression, with reduced kidney fibrosis and plasma creatinine levels 90 days after the AKI event. This effect was associated with decreased parenchyma inflammation at day $14 .{ }^{19}$ Altogether, the pre-clinical evidence proposed that the pro-inflammatory signal transduction mediated by MR is a plausible target to prevent the chronic alterations induced by ischemic AKI.

The benefit of MRAs in wound healing, favoring M2 repair macrophages over inflammatory M1 macrophages extends beyond the kidney, as reported for stroke 21,22 aldosterone-salt induced hypertension ${ }^{23,24}$, cardiac remodeling ${ }^{25-27}$, and skin injury (Jaisser $F$, personal data).

\section{Pre-clinical data: MR antagonism in kidney fibrosis and CKD progression}

Kidney fibrosis is the common end-point of CKD from various etiologies. Several experimental models have been used to mimic the human disease, leading to kidney fibrosis, in which the role of aldosterone and MR activation has been evaluated. A pioneer 
study by Greene et al. reported that ACE and AT1 receptor inhibition ameliorated the proteinuria and glomerulosclerosis in the subtotal nephrectomy model. ${ }^{28}$ The addition of aldosterone to rats with subtotal nephrectomy and ACE/AT1 antagonist treatment reversed their protective effects. Moreover, spironolactone treatment of subtotal nephrectomized rats transiently reduced proteinuria, lowered blood pressure, and reduced cardiac hypertrophy. ${ }^{28}$ MR antagonism not only prevents glomerulosclerosis in this remnant kidney model but also induces its regression. ${ }^{29}$ Recently, it was shown that the non-steroidal aldosterone antagonist Ly also protects against albuminuria and kidney hypertrophy in the remnant kidney model, with better efficacy than eplerenone. However, a beneficial effect on collagen deposition and macrophage infiltration was observed only when it was given together with losartan, possibly through a better antihypertensive effect. ${ }^{30}$

Since a common feature in the aforementioned studies is the positive effect of MRAs on proteinuria, it was suspected that MR inhibition was acting through an effect on podocyte health, therefore maintaining the glomerular filtration barrier. In the Dahl salt hypertensive rat model, eplerenone had a modest effect on reducing blood pressure, but it reduced podocyte damage and effacement and delayed the progression of proteinuria and glomerulosclerosis. ${ }^{31}$ Similarly, the non-steroidal MRA CS-3150 prevented glomerulosclerosis, tubular injury, and fibrosis. ${ }^{32} \mathrm{MR}$ activation in podocytes may occur by aldosterone-independent mechanisms. In 2008, Shibata et al. showed that a constitutively active form of Rac1 induced MR nuclear translocation and activation in podocytes. ${ }^{33}$ Moreover, mice with globally increased Rac1 activity presented severe albuminuria and podocyte injury, which were prevented by the MRA eplerenone. ${ }^{33}$

MR antagonism as a strategy to treat or delay glomerulonephritis progression has been evaluated. Spironolactone reduced proteinuria in a model of proliferative 
glomerulonephritis induced by anti Thy1.1 antibody administration and this effect was potentiated to prevent fibrosis in combination with cilazapril. ${ }^{34}$ In the same model, spironolactone treatment reduced TGF-beta staining and the injury score in the artery and glomerulus, and most importantly it also reduced proliferation. ${ }^{35}$ More recently, it was questioned whether aldosterone blockade not only prevents glomerulonephritis due to the effect on proliferation but also because of an anti-inflammatory effect. Indeed, eplerenone administration in the anti-Thy1.1 model inhibited glomerular macrophage infiltration, MCP-1 expression, and mesangial phenotypic activation. ${ }^{36}$

The administration of anti-GBM antibodies is another strategy used to mimic glomerulonephritis. In this animal model, eplerenone administration reduced albuminuria, glomerular sclerosis, and glomerular crescents, accompanied by reduced infiltration of $\mathrm{CD}^{+}$and $\mathrm{CD}^{+} \mathrm{T}$ cells and macrophages. ${ }^{37,38}$ Huang et al. assessed the severity of glomerulonephritis in mice receiving anti-GBM antibodies and specific deletion of the MR, either in podocytes or myeloid cells, to evaluate whether the MRs expressed in podocytes or inflammatory cells were responsible for the beneficial effect. Myeloid-specific MR deficiency or eplerenone treatment had no effect on the severity of proteinuria. However, a reduction in cystatin $\mathrm{C}$ levels and crescent numbers and reduced infiltration of macrophages and neutrophils to the kidney was observed. A reduction in pro-inflammatory cytokine levels, tubular damage, and renal fibrosis was also documented. Podocyte-specific MR deletion had no effect in ameliorating anti-GBM glomerulonephritis. ${ }^{38}$ Therefore, MRs expressed in inflammatory cells play a key role in the progression of glomerulonephritis. The novel non-steroidal MRA BR-4628 also efficiently improved renal function, prevented glomerular tuft damage, and reduced glomerular crescents by $50 \%$. The inflammatory component was also affected in the kidney, with lower levels of infiltrated macrophages 
and $\mathrm{T}$ cells, associated with reduced pro-inflammatory cytokine expression. Therefore, these authors found that BR-4628 provided similar protection from glomerulonephritis as eplerenone without altering tubular salt handling. ${ }^{39}$

Hypertension is associated with kidney injury. The benefit of MR antagonism against hypertension-induced kidney injury has been tested in several rodent models and has proven to be independent from blood pressure control. In the stroke-prone spontaneously hypertensive rat, which develops nephrosclerotic lesions and proteinuria, spironolactone administration effectively prevented kidney damage, even if the increase in blood pressure was not affected. ${ }^{40} \mathrm{~A}$ similar effect on proteinuria and glomerular sclerosis was described in the radiation injury hypertensive model, without an effect on blood pressure. ${ }^{41}$ In spontaneously hypertensive rats, chronic NOS inhibition with L-NAME exacerbates nephrosclerotic lesions. Eplerenone administration ameliorated proteinuria and glomerular, arteriolar, and tubulointerstitial lesions, despite having no effect on systemic or renal hemodynamics. ${ }^{42}$ In the same model of NOS inhibition, it was further observed that inflammatory cell infiltration to the kidney was inhibited by spironolactone ${ }^{43}$ In the hypertensive kidney injury induced by aldosterone-salt plus unilateral nephrectomy model, eplerenone attenuated hypertension and efficiently reduced albuminuria, kidney fibrosis, glomerular injury, and pro-inflammatory gene expression in Sprague-Dawley rats. ${ }^{44}$ The novel non-steroidal MRAs SM-368229, CS-3150, and AZD9977 have also shown favorable effects on renal pathology in this context. ${ }^{45,46,47}$ In a similar model that uses DOCA administration instead of aldosterone, specific MR deletion in the endothelium ameliorated cardiac remodeling, but not renal injury, suggesting that the MR in the endothelium does not play a crucial role in this type of kidney injury. ${ }^{48}$ 
A classic model of kidney fibrosis is unilateral ureteral obstruction (UUO). Trachtman et al. showed that spironolactone was able to reduce kidney fibrosis in C57BL/6 mice with two weeks of UUO. ${ }^{49}$ In rats with UUO, eplerenone improved renal fibrosis and inflammation, reduced monocyte and macrophage infiltration and interstitial cell proliferation, and reduced oxidative stress. ${ }^{50}$ The positive effects of eplerenone are not restricted to the obstructed kidney, as it also decreased macrophage infiltration, collagen deposition, and PCNA expression in the contralateral kidney. ${ }^{51}$

In summary, MRAs have beneficial effects in hypertensive, glomerular, and fibrotic kidney disease. The underlying mechanisms are detailed below.

\section{Pre-clinical data: Benefit of MR blockade in diabetic nephropathy}

Kidney disease is a frequent complication in diabetic patients. It is estimated that $40 \%$ of end-stage renal disease cases are attributable to complications of diabetic kidney disease. ${ }^{52}$ The most common model for type 1 diabetes in rodents is pancreatic beta-cell depletion by streptozotocin (STZ) administration. In 2004, Fujisawa et al. showed that spironolactone administration for three weeks reduced renal collagen deposition in the glomerular, tubulointerstitial, and perivascular areas in STZ-induced diabetic rats. ${ }^{53}$ The protective effect of MRAs in diabetic nephropathy was corroborated in further studies. ${ }^{54,55,2,56}$ Eplerenone also reduced glomerular volume and glomerular fibrosis in STZtreated hypertensive rats. ${ }^{57}$ The protective effect may be mediated by the restoration of G6PD activity and oxidative stress reduction by spironolactone..$^{58}$

Type 2 diabetes is often studied in rodent models with genetic alterations that lead to metabolic disorders. Eplerenone reduced albuminuria, glomerular hypertrophy, and mesangial expansion in the $\mathrm{db} / \mathrm{db}$ diabetic mouse model. ${ }^{54}$ Similarly, The novel MRA 
AZD9977 reduced albuminuria and kidney histology changes in $\mathrm{db} / \mathrm{db}$ mice. ${ }^{46}$ The addition of eplerenone to an ACE inhibitor in $\mathrm{db} / \mathrm{db}$ mice had additional beneficial effects, improving albuminuria, glomerulosclerosis, podocyte injury, and renal fibrosis. ${ }^{59}$

In the rat, a commonly used model for diabetic kidney disease is the Otuska LongEvans Tokushima Fatty rat (OLEFT). In this model, spironolactone decreased albuminuria and ameliorated glomerulosclerosis, macrophage infiltration, and MCP-1 upregulation. ${ }^{60}$ Moreover, Han et al. showed that the antifibrotic effect of spironolactone in this model may be mediated by CTGF through a TGF-beta1-independent pathway. ${ }^{60} \mathrm{~A}$ synergistic effect to prevent podocyte injury has been observed with a combination of enalapril and eplerenone ${ }^{61}$ or with telmisartan. ${ }^{62}$ In the Zucker-obese rat, finerenone reduced proteinuria and renal NGAL expression. ${ }^{63}$ In a severe model that combines obesity, hypertension, and high salt (SHR/cps rat), massive proteinuria, severe renal lesions, and podocyte injury are observed; eplerenone dramatically ameliorated proteinuria and renal injury in these animals ${ }^{64}$ Mice with obesity induced by a high fat diet develop kidney injury, characterized by glomerular hypercellularity, mesangium expansion, albuminuria, and increased rho kinase activity; all of these alterations were attenuated by eplerenone. ${ }^{65}$ In cultured mesangial cells, high glucose increases Rac1 and MR transcriptional activity. ${ }^{66}$ In accordance with these observations, the inhibition of Rac1 reduced MR activity in the kidney and mitigated renal pathology in a mouse model of obesity-related type 2 diabetes (KKA(y) mouse), even if plasma aldosterone levels were unchanged. ${ }^{66}$

\section{Pre-clinical data: Calcineurin inhibitor toxicity and kidney transplantation}

Calcineurin inhibitors (CNI) are widely used in kidney-transplant patients as immunosuppressive drugs. Since the introduction of CNI in the clinic, the lifespan of the 
grafts has been significantly extended. The use of CNI is often limited due to its acute or chronic nephrotoxic effects. Acute CNI nephrotoxicity is characterized by potent, but reversible, vasoconstriction of the afferent arteriole that leads to a reduction in renal blood flow and the GFR. ${ }^{67}$ In 1987, it was shown that spironolactone treatment of rats with acute cyclosporine A (CsA) nephrotoxicity was able to preserve kidney function. ${ }^{68}$ Later, PerezRojas et al. showed that spironolactone not only prevents the decrease in GFR but also prevents the fall in renal blood flow. ${ }^{69}$ Similar effects were observed with eplerenone. ${ }^{70}$ More recently, it was shown that the MRs in SMCs play a key role in the vasoconstriction induced by CsA. MR deletion in SMCs prevented the acute kidney dysfunction and injury induced by CsA and blunted the CsA-induced phosphorylation of contractile proteins, thus normalizing renal vascular resistance. ${ }^{71}$

During chronic CNI nephrotoxicity, tubulointerstitial fibrosis, arteriolopathy, proteinuria, and a progressive decrease in GFR occur and contribute to graft loss. The chronic reduction in renal blood flow and GFR induced by CNI are prevented by spironolactone. ${ }^{69}$ This effect is due to modulation of the expression of prorenin, the endothelin-A receptor, and the endothelin-B receptor by the MRA, favoring vasodilation. ${ }^{69}$ Feria et al. showed that CNI-induced tubulointerstitial fibrosis is prevented by spironolactone. ${ }^{72}$ Nielsen et al. showed an increased volume fraction of the interstitial space in CsA-treated rats which was prevented by MR antagonism. ${ }^{73}$ Moreover, Pérez-Rojas et al. showed that spironolactone can slow the progression of kidney injury in established CNI-induced kidney injury ${ }^{74}$ The up-regulation of TGF-beta, collagen I, and fibronectin mRNA levels induced by CsA was prevented by spironolactone. ${ }^{74}$ MR antagonism also protected against CNI-induced arteriolopathy. ${ }^{72,73}$ 
Concerning kidney transplantation, spironolactone administration from two days before up to 12 weeks post-transplantation significantly ameliorated vasculopathy and glomerular macrophage influx and tended to reduce proteinuria and glomerulosclerosis in a model of chronic allograft dysfunction in the Dark Agouti to Wistar Furth rat. ${ }^{75}$ However, interstitial fibrosis, creatinine clearance, and blood pressure were not affected. Other authors failed to detect any protection against glomerulosclerosis or interstitial fibrosis with MR antagonism or aldosterone synthase inhibition in a rat model of allograft injury in male Fisher-344 rats to male Lewis rats. ${ }^{76}$

\section{Pre-clinical data: Benefit of MRAs on the comorbidities of CKD}

The positive effect of MR inhibition may not be restricted to kidney protection, since spironolactone also prevented increases in cardiomyocyte size in both ventricles, despite no benefit on kidney function or blood pressure control in a subtotal nephrectomy CKD model in the rat. ${ }^{77}$ Similarly, we reported that finerenone prevents cardiac diastolic dysfunction in mice with CKD despite maintained renal dysfunction. ${ }^{78}$ In the Zucker rat, a model of metabolic syndrome cardiorenal injury, finerenone reduced cardiac hypertrophy, fibrosis, and dysfunction. ${ }^{63}$ Cardiac diastolic dysfunction and vascular injury associated with diet-induced obesity are also prevented by MR inhibition. ${ }^{79,79,80} \mathrm{MR}$ antagonism prevented diabetic neuropathy, as shown by improved motor-nerve conduction velocity and mean myelin area after eight weeks of eplerenone treatment in STZ-induced diabetic rats. ${ }^{81}$

Major pathophysiological mechanisms involved in the impact of MRs on kidney diseases:

Pre-clinical data: MRs and oxidative stress 
Multiple studies have shown the impact of aldosterone/MR-induced oxidative stress on detrimental consequences in the kidney. DOCA-salt administration for six weeks causes oxidative DNA damage and increases the mutagenic DNA modification 8-oxodG in the kidney. ${ }^{82}$ Aldosterone infusion in the rat produces an MR-dependent increase in NADPH oxidase activity and ROS generation and increased expression of p67phox, p22phox, Nox4, Gp91phox, p47phox, and Rac1 in the kidney. ${ }^{83}{ }^{84}$ Mouse peritoneal macrophages and aortic segments from aldosterone-treated mice exhibit increased superoxide anion formation and increased translocation of the NADPH oxidase subunit p47phox to the macrophage plasma membrane. ${ }^{85}$ The incubation of human mononuclear leukocytes with $10 \mathrm{nM}$ aldosterone increases p22phox expression, an effect blocked by the MRA canrenone. ${ }^{86} \mathrm{MR}$ activation in SMCs and endothelial cells is associated with ROS production by increasing the expression and activity of NADPH oxidases. ${ }^{87,88,89,90}$ The oxidative stress induced in SMCs in turn promotes cell senescence. ${ }^{91}$ MRs in SMCs contribute to angiotensin II-induced vascular oxidative stress. ${ }^{92}$ In endothelial cells, aldosterone decreases the expression of G6PD, which is a critical regulator of the redox state, shifting the balance towards increased oxidative stress. ${ }^{93}$ In pulmonary artery endothelial cells, aldosterone increases ROS, which in turn modifies the cysteinyl thiols in the eNOS-activating region of the ET(B) receptor, thus decreasing endothelin-1 stimulated eNOS activity. These effects have physiological consequences on the local hemodynamics in pulmonary arterial hypertension ${ }^{94}$ and in kidney ischemia/reperfusion injury. ${ }^{12,11}$

In rat mesangial cells, aldosterone directly stimulates superoxide anion generation, which is accompanied by an increase in NADPH oxidase activity and translocation of p47phox and p67phox to the cell membrane. ${ }^{95}$ In addition, aldosterone induces mesangial- 
cell apoptosis and the administration of an antioxidant or MRA attenuates the proapoptotic effects of aldosterone. ${ }^{96}$

In the White Large pig, MR antagonism reduced the increase in MDA levels induced by ischemic injury. ${ }^{13}$ Patients with primary aldosteronism display higher NADPH oxidase Nox 2 plasma and urinary isoprostane levels than essential hypertensive patients. ${ }^{97}$ Moreover, reduced oxidative stress is observed in diabetic or kidney transplant patients treated with an MR antagonist. ${ }^{98,99}$

\section{Pre-clinical data: MRs and inflammation}

A role for MR signaling in inflammation has been suggested since early studies showing that the treatment of rats with aldosterone/salt causes perivascular leukocyte infiltration and increased expression of osteopontin, MCP-1, IL-6, and IL-1 $\beta$ in the kidney, whereas MR antagonism prevents this pro-inflammatory state. ${ }^{44}$ The endothelial MR participates in the inflammatory process by increasing adhesion molecule-1 expression. ${ }^{100}$ There is a direct effect of MRAs on inflammatory cells in human PBMCs stimulated with LPS, as spironolactone inhibits the transcription of TNF-alpha, IL-6, and IFN-gamma. ${ }^{100}$ Similarly, the pro-inflammatory effect of angiotensin II on human PBMCs is prevented by MRAs. ${ }^{101}$

Mice lacking the MR in myeloid cells displayed unaffected macrophage infiltration in the heart following DOCA treatment, showing that myeloid MRs are not involved in the migration capacity of the macrophages but probably in differentiation. ${ }^{23}$ In accordance with this hypothesis, pharmacological or genetic MR inhibition in cultured macrophages reduced the levels of pro-inflammatory M1-markers and increased those of anti-inflammatory M2markers. ${ }^{102}$ In peritoneal macrophages, MR deficiency synergizes with IL-4 or an agonist of 
PPARgamma to enhance alternative $\mathrm{M} 2$ activation. $^{25}$ In vivo, MR deficiency in macrophages mimics the effects of MRAs and protects against cardiac hypertrophy, fibrosis, and vascular damage caused by L-NAME/Ang II. ${ }^{25}$ In cerebral ischemia, myeloid MR deficiency reduces the infarct volume and macrophage infiltration in the ischemic core, consistent with reduced M1 and increased M2 marker levels. ${ }^{21}$ A recent report by our group showed that MR inhibition acts by influencing IL-4 receptor signaling, promoting macrophage differentiation to an M2 phenotype. These effects were protective against the AKI to CKD transition. ${ }^{19}$ In macrophages, MR gene ablation prevents the activation of cJun and cFos in response to pro-inflammatory stimuli ${ }^{24,103}$. Aldosterone increases NGAL expression in macrophages, dendritic cells, and PBMCs. Mice depleted for NGAL in their immune cells are protected against aldosterone-salt-induced cardiac remodeling and inflammation, suggesting that NGAL mediates the pro-inflammatory effects of the MR. ${ }^{104}$

T-cell MR knockout mice showed lower cardiac hypertrophy, fibrosis, and dysfunction than littermate control mice after abdominal aortic constriction, suggesting that MRs in T cells may also play a pro-inflammatory role. In vitro studies showed that MR inhibition repressed T-cell activation, whereas MR overexpression had the opposite effect. ${ }^{105} \mathrm{MR}$ inhibition in T cells had a similar protective effect against hypertension in the AngII-salt model. ${ }^{105}$ Furthermore, MR antagonism with spironolactone in a hypertension rat model reduced heart and kidney damage due to a blockade of Th17 polarization and the induction of regulatory $\mathrm{T}$ cells. ${ }^{106} \mathrm{In}$ dendritic cells, MR stimulation with aldosterone induces the secretion of IL- 6 and TGF- $\beta$, two proinflammatory cytokines that can polarize the adaptive immune response towards a Th17 phenotype. ${ }^{107}$

\section{Pre-clinical data: MR and renal hemodynamic alterations}


The MR contributes to the regulation of vascular tone. ${ }^{8,10,69}$ We recently explored the role of SMC-MRs in kidney injury. We showed that SMC-MR-KO mice are protected against ischemia-induced renal injury through a mechanism involving oxidative stress and Rac1 activation ${ }^{13}$. In addition, MR deficiency in SMCs was also protective in an acute model of CsA nephrotoxicity. ${ }^{71}$ This protection was attributed to blunted vascular L-type calcium channel activity in SMC-MR-KO mice, resulting in decreased renal artery vasoconstriction and an overall improvement in renal hemodynamics. ${ }^{106}$

\section{Pre-clinical data: MR and fibrosis}

In uni-nephrectomized rats, aldosterone administration is associated with an increase in TGF- $\beta$, collagen, and connective tissue growth factor expression that is accompanied by medullary and cortical fibrosis. ${ }^{108,109}$. Aldosterone influences the production of plasminogen activator inhibitor-1 and this effect is associated with glomerulosclerosis. ${ }^{41}$ Aldosterone has been reported to induce collagen synthesis in cultured fibroblasts ${ }^{110,111}$ and glomerular mesangial cells. ${ }^{112}$ In cultured fibroblast expressing MRs, aldosterone addition increases ERK1/2 phosphorylation and the mRNA levels of collagens I, III, and IV. ${ }^{113}$ Moreover, aldosterone stimulates fibronectin synthesis through MR-dependent activation of the JNK kinase and subsequent phosphorylation of the AP1 transcription factor c-Jun. ${ }^{114}$ Aldosterone induces OPN expression in kidney fibroblasts $^{115}$; accordingly, OPN plasma levels are higher in patients with primary aldosteronism. ${ }^{116}$ In addition, MR activation in renal fibroblasts results in rapid activation of growth-factor receptors and the induction of PI3K/MAPK signaling, which stimulates proliferation. ${ }^{117}$ This evidence suggests that increased MR activation may promote kidney fibrosis by inducing fibroblast proliferation and the production of pro-fibrotic 
molecules. MR activation in SMCs increases the expression of mediators of extracellular matrix deposition, such as integrin alpha 5, galectin-3, and placental growth factor. ${ }^{118-120}$

Mice deficient for NGAL are protected from aldosterone-induced increases in procollagen I expression and collagen fiber deposition in the coronary vessels and aorta ${ }^{121}$ and kidney (Jaisser F, unpublished data). NGAL addition to human fibroblasts increases the production of galectin-3 and collagen $\mathrm{I}^{121}$ and is required for the profibrotic effects of aldosterone. ${ }^{122}$ Galectin-3 also mediates the pro-fibrotic effects of aldosterone through the $\mathrm{MR}$, as galectin-3 $\mathrm{KO}$ mice are protected against aldosterone-induced kidney fibrosis. ${ }^{123}$ Excessive SGK1 expression is observed in several kidney fibrotic diseases. MR-induced SGK-1 expression inhibits the degradation of Smad2/3, mediators of TGF-beta signaling, thus contributing to the development of fibrosis. ${ }^{124}$ MRs may also act through the EGF receptor, directly contributing to fibrosis. ${ }^{125}$

Figure 1 summarizes the mode of action of MR antagonists and its effects on different cell types, as well as the clinical settings where MR antagonism may have a beneficial effect.

\section{Clinical data supporting a benefit of MR antagonists in kidney diseases: past and current clinical trials}

Clinical data: Beneficial impact of MRAs in limiting the progression of CKD

Over the past two decades, several RCTs have reported a substantial antiproteinuric effect and a possible major renoprotective effect of MRAs in CKD. Two meta-analyses including studies published from 2002 to $2011^{126}$ and 2005 to $2014^{127}$ showed that MRAs effectively reduce proteinuria when used in combination with angiotensin converting enzyme inhibitors (ACEis) and angiotensin receptor blockers (ARBs). As mentioned above, 
the beneficial impact of MRAs may be of particular interest in the setting of diabetic nephropathy (DN). A meta-analysis analyzing the impact of spironolactone addition to ACEi or ARB in patients with DN confirmed a significant reduction of 24-hour urinary albumin/protein excretion in eight studies and a significantly higher reduction of the urinary albumin/creatinine ratio in three. ${ }^{128}$ Of note, a significant reduction in blood pressure was also reported so one cannot exclude a reduction of proteinuria partly mediated by the blood pressure reduction. The ARTS-DN Study demonstrated a dose-dependent reduction in proteinuria in patients with $\mathrm{DN}$ receiving $\mathrm{ACEis}$ or $\mathrm{ARBs}$ in combination with finerenone. ${ }^{129}$ In this trial, hypertension with mean sitting SBP $>=160 \mathrm{mmHg}$ or mean sitting DBP >=100 mmHg at the screening visit was considered as an exclusion criteria. At baseline, mean BP was $<140 / 80 \mathrm{mmHg}$ in the different arms of treatment. Moreover, the placebo least squares corrected mean differences in SBP from baseline to day 90 in the finerenone groups were slight. Finally, the post hoc analysis showed that no meaningful correlation was observed across all treatment groups between the proteinuria change and the change in SBP from baseline to day 90.

An added antiproteinuric effect of MRAs was also reported in cases of non-diabetic nephropathy, such as idiopathic chronic glomerulonephritis. ${ }^{130,131}$

Of note, the available studies were not designed to demonstrate a beneficial impact of MRAs on long-term renal outcomes, in particular time to renal death. Most of the studies evaluated the reduction of proteinuria with MRAs. The association between the reduction of proteinuria and the decrease of CKD progression is reported. ${ }^{132}{ }^{133}$. In 2009 the FDA and the National Kidney Foundation ${ }^{134}$, and again in 2012 the FDA and the American Society of Nephrology's glomerular disease advisory group, considered that for now, proteinuria could not be considered as an established surrogate endpoint and that further studies were 
needed $^{133}$. To date, proteinuria is included in the surrogate endpoints that were the basis of drug approval or licensure by the FDA only in the settings of the following renal pathologies: primary glomerular disease associated with nephrotic syndrome and primary immunoglobulin A nephropathy ${ }^{135}$.

The necessity to develop studies with surrogate outcomes is recognized in order to improve the prognosis of CKD patients. ${ }^{136}$ In his editorial ${ }^{136}$, Roy-Chaudhury stressed again that nephrology is one of the medical specialties with the lowest number of RCT. ${ }^{137}$ Moreover, he emphasized the fact that surrogate markers should be developed and validated in order to reduce the follow-up period of RCT. Outcomes such as renal death or doubling of creatinine preclude investigators from conducting RCT evaluating new therapeutic strategies. In trials evaluating interventions to slow CKD progression, the 30 to $40 \%$ reduction of estimated glomerular filtration rate (eGFR) probably is reliable surrogate marker. ${ }^{138}$

From a safety point of view, available data indicate a good short-term safety of MRAs in the setting of CKD. Indeed, the short-term impact of MRAs on the eGFR was considered to be either neutral in the meta-analysis of Boliglano et al. $(n=528$ patients, mean difference of $-2.55 \mathrm{~mL} / \mathrm{min} / 1.73 \mathrm{~m}^{2}, 95 \% \mathrm{CI}[-5.67 \text { to } 0.51]^{126}$ or slightly deleterious in the meta-analysis of Currie et al. $\left(n=1,646\right.$ patients, mean difference of $-3.2 \mathrm{~mL} / \mathrm{min} / 1.73 \mathrm{~m}^{2}$ $95 \%$ CI $[-5.4$, to -1.0$] .{ }^{127}$

From an efficacy point of view, no data are currently available to evaluate the impact of MRAs on long-term renal protection. A RCT aiming to enroll a total of 4,800 patients with $\mathrm{DN}$ to assess the effect of finerenone on the progression of CKD is ongoing (FIDELIO NCT02540993). The primary outcome is time to the first occurrence of the composite 
endpoint of the onset of kidney failure, a sustained decrease of eGFR $\geq 40 \%$ from baseline over at least four weeks, and renal death. A follow-up of up to 48 months is planned.

\section{Clinical data: Improvement of CV outcomes by MRAs in CKD/ESRD patients}

* Potential beneficial impact of MRAs in heart failure among CKD patients

The life-saving effect of MRA in heart failure with altered left ventricular function and post-myocardial infarction is well established ${ }^{139}$ and the prescription of MRAs is included in the international guidelines of treatment of heart failure ${ }^{140}$. MRAs possibly have also a beneficial effect in heart failure with preserved left ventricular function $\left(\right.$ TOPCAT $^{141}$ ). Only few studies have assessed the beneficial impact of MRAs on CV outcomes in CKD or dialysis patients.

In a post-hoc analysis of the EMPHASIS-HF study ${ }^{142}$, Eschalier et al. reported that the HR for the primary outcome (hospitalization for HF or cardiovascular mortality) in the eplerenone group as compared with the placebo group was $0.69,95 \%$ CI [0.56-0.86]; in patients without CKD (defined by eGFR $<60 \mathrm{ml} / \mathrm{min} / 1.73 \mathrm{~m}^{2}$ ), and $0.62,95 \%$ CI [0.490.79] in patients with CKD. The interaction test was not significant, so MRAs probably are as effective in CKD as in non-CKD patients for the treatment of heart failure. Of note, the EMPHASIS-HF trial enrolled patients at least 55 years old with heart failure and reduced ejection fraction (HF-REF), with an estimated glomerular filtration rate (eGFR) >30 $\mathrm{ml} / \mathrm{min} / 1.73 \mathrm{~m}^{2}$ and serum potassium $<5.0 \mathrm{mmol} / \mathrm{l}$. In patients with $\mathrm{CKD}$, the incidence of potassium $>5.5 \mathrm{mmol} / \mathrm{l}$ in patients receiving eplerenone increased in comparison to placebo (16.6\% versus $9.3 \%, \mathrm{p}=0.002)$. There was no increase in the proportion of patients with a serum potassium $>6.0 \mathrm{mmol} / \mathrm{l}(1.9 \%$ vs $3.3 \%, \mathrm{p}=0.29$ for the comparison between the eplerenone and the placebo groups). When comparing the patients treated with eplerenone 
with or without $\mathrm{CKD}$, there was a decrease in incident potassium $>6.0 \mathrm{mmol} / \mathrm{l}$, $(1.9 \% \mathrm{vs}$ $2.74 \%, \mathrm{p}=0.01$ ), but an increase in hyperkalemia leading to treatment discontinuation, ( $1.15 \%$ vs $1.08 \%, p=0.01$, in eplerenone patients with CKD compared with patients without CKD).

A large recent Swedish registry trial reported that among patients with myocardial infarction and heart failure ${ }^{143}$ (Swedish myocardial infarction registry, SWEDEHEART, 2005-2014), MRAs were under prescribed at discharge (only 9.9\%), in particular among patients with eGFR $<60 \mathrm{~mL} / \mathrm{min}(8.6 \%$, vs $11.4 \%$ among patients with eGFR $>60 \mathrm{~mL} / \mathrm{min})$. The rate of prescription according to CKD stages is not available. Of note, the use of MRA was associated with better long-term survival (all-cause mortality up to 3 years) in patients with left ventricular ejection fraction $(\mathrm{LVEF})<40 \%$ but not in those with $\mathrm{LVEF} \geq 50 \%$. Moreover, the mortality risk was similar in MRA-treated patients with (HR 0.92, 95\% CI [0.85-0.99]) or without (HR 0.96, 95\% CI [0.88-1.05]) CKD.

The safety of finerenone was evaluated in the setting of heart failure among patients with mild CKD (mean baseline eGFR $69.1 \pm 8.43 \mathrm{ml} / \mathrm{min} / 1.73 \mathrm{~m}^{2}$ ) and moderate CKD (mean baseline eGFR $47.0 \pm 10.0 \mathrm{ml} / \mathrm{min} / 1.73 \mathrm{~m}^{2}$ ) in the Miner Alocorticoid-Receptor Antagonist Tolerability Study (ARTS). ${ }^{144}$ Finerenone decreased the levels of B-type natriuretic peptide (BNP), amino-terminal proBNP, and albuminuria to the same extent as spironolactone. Finerenone was associated with significantly smaller increases in potassium levels than spironolactone (from 0.04 to $0.30 \mathrm{mmol} / \mathrm{L}$, depending on the dose of finerenone, and $0.45 \mathrm{mmol} / \mathrm{L}$ for spironolactone, respectively, $\mathrm{p}<0.0001$ to 0.0107 ) and a lower incidence of hyperkalemia (5.3 and $12.7 \%$, respectively, $\mathrm{p}=0.048$ ).

\footnotetext{
* Cardiac and vascular CKD-related abnormalities
} 
Scarce data are available concerning the potential beneficial impact of MRAs on CV outcomes among patients with CKD, either in dialysis or not.

In patients with stage 2-3 CKD, the administration of spironolactone for 40 weeks was associated with a significant improvement of left ventricular hypertrophy and arterial stiffness $^{145}$, as well as markers of regional LV systolic and diastolic function, relative to placebo. ${ }^{146}$ In patients with stage 3-4 CKD (mean eGFR $36+/-11 \mathrm{~mL} / \mathrm{min} / 1.73 \mathrm{~m}^{2}$ ), the addition of eplerenone to standard medication did not improve pulse wave velocity after 24 weeks, but significantly attenuated pulse wave reflections (as measured by the Augmentation Index). ${ }^{147}$ The increased pulse wave velocity observed in CKD is mainly related to higher arterial stiffness of larger conduit vessels. If structural changes of the arterial wall are partly mediated by the $\mathrm{MR}^{148}$, but the benefit from MRAs on pulse wave velocity probably need longer interventions to be detected. In contrast, improvement of the Augmentation Index probably reflects the rapid functional effect of eplerenone on the peripheral resistance of the small resistance vessels. Whether long-term use of MRAs will modify vessel structure is still to be determined in clinical trials.

In a limited number of patients with reduced ejection fraction, the administration of spironolactone during 6 months significantly improved the ejection fraction and the left ventricular mass in hemodialysis patients in comparison with placebo ${ }^{149}$, and improved the ejection fraction in patients on continuous ambulatory peritoneal dialysis ${ }^{150}$. Of course, the limited number of patients precludes drawing definitive conclusions and larger studies are needed to evaluate the effects of MRAs among patients with chronic heart failure in dialysis. Of note, from a clinical and methodological point of view, chronic heart failure may be difficult to define in dialysis because the ejection fraction is closely dependent on the dry weight ${ }^{151}$. 
In hemodialysis, the recently published MIREnDa RCT (NCT01691053) did not reported a significant change in left ventricular mass index measured by cardiac magnetic resonance imaging with spironolactone administrated for 9 months (in press 10.1016/j.kint.2018.11.025). Moreover, the 6 months administration of spironolactone did not significantly change the diastolic function of patients in hemodialysis in the recent SPin-D RCT ${ }^{152}$.

Large RCT are needed to investigate the effect of MRAs on hard CV outcomes. The ongoing RCT ALCHEMIST (NCT01848639) will provide very informative data.

\section{* Cardiovascular morbi-mortality among CKD/ESRD patients}

Regarding CV morbi-mortality, a meta-analysis of nine trials (829 patients) published between 2005 and 2015 on patients undergoing dialysis demonstrated a decreased risk of CV mortality (RR 0.34 (95\% CI, 0.15-0.75)) for MRA-treated patients relative to controls. ${ }^{153}$ Nevertheless, the trials included a limited number of patients and the conclusions are still uncertain. A large multicenter RCT is currently being conducted among patients on hemodialysis (ALCHEMIST: NCT01848639) to assess the efficacy of spironolactone in reducing CV-associated morbidity and mortality. In CKD, a RCT aiming to enroll a total of 6,400 patients with $\mathrm{DN}$ is ongoing to assess the effect of finerenone on the occurrence of CV outcomes (FIGARO NCT02545049). The primary outcome is time to the first occurrence of the composite endpoint of $\mathrm{CV}$ death and non-fatal $\mathrm{CV}$ events (myocardial infarction, stroke, or hospitalization for heart failure). The ongoing RCT BARACK D (Benefits of Aldosterone Receptor Antagonism in Chronic Kidney Disease) is an ongoing 36-month study of 2,616 patients with stage $3 \mathrm{~b}$ CKD to compare the efficacy of the addition of spironolactone $25 \mathrm{mg}$ once daily to routine care on mortality and $\mathrm{CV}$ 
outcomes versus routine care alone. ${ }^{154} \mathrm{CKD}$ progression will be evaluated as a secondary outcome. Of note, another RCT (STOP-CKD ${ }^{155}$ ) aimed to evaluate the change in arterial stiffness (pulse wave velocity) as a surrogate marker of $\mathrm{CV}$ risk among stage $3 \mathrm{CKD}$ patients with spironolactone in the setting of primary care, but ended prematurely due to limited recruitment. ${ }^{156}$ The ongoing clinical trials evaluating cardiovascular outcomes with MRAs among CKD patients are summarized in Table 2.

Clinical data: Focus on kidney transplantation (KT): evidence for IRI prevention and prevention of chronic graft dysfunction by MRAs

\section{* Prevention of IRI}

A pilot clinical trial on living-donor KT demonstrated a beneficial effect of spironolactone on renal oxidative stress when initiated in recipients one day prior to KT and administered for three days following KT. ${ }^{98}$ Given that graft function was good in both arms (as expected in the setting of living donor donation), the investigators did not observe significantly better short-term renal function in the MRA group relative to that of the placebo group. Nevertheless, urinary levels of hydrogen peroxide (a biomarker of oxidative stress) were lower in the MRA group.

\section{*Limiting IRI-induced chronic kidney dysfunction after KT}

We are currently conducting a multicenter RCT to assess the impact of short-term administration of eplerenone (immediately before and four days after KT) on three-month renal graft function in patients receiving a graft from an expanded-criteria donor (EPURE: NCT02490904) ${ }^{157}$. We plan to randomize 132 patients. The graft GFR is assessed at three months by measuring iohexol clearance. Secondary outcomes include the occurrence of 
delayed graft function and immediate or slow graft recovery, as well as the occurrence of hyperkalemia.

\section{*Limiting cyclosporine-induced nephropathy}

A recent RCT with eplerenone reported promising results in limiting the progression of biopsy-proven chronic graft nephropathy in children. ${ }^{158}$ A RCT (SPIREN trial NCT01602861) is currently being conducted to evaluate the impact of the administration of spironolactone for three years among 170 prevalent kidney transplant patients. The primary endpoint is GFR measured by chrome-EDTA clearance. Secondary outcomes are proteinuria, the amount of interstitial fibrosis in graft biopsies, and cardiovascular events. ${ }^{159}$

\section{Clinical data: MRAs for IRI prevention outside the scope of kidney transplantation}

\section{*Cardiac surgery}

In the setting of cardiac surgery, the administration of $100 \mathrm{mg}$ spironolactone the day before the intervention and $25 \mathrm{mg} / \mathrm{d}$ for three days after failed to prevent post-operative AKI. ${ }^{160}$ Indeed a trend towards risk mediated by the use of spironolactone was observed. ${ }^{160}$ However, the association of the MRA with outcome in this trial may have been underestimated because of the higher proportion of diabetic patients in the MRA arm (31 vs $18 \%, \mathrm{p}=0.02)$, AKI was mostly driven by AKI stage 1 and the planned sample size was not achieved, potentially underpowering the study. In a RCT aimed to test if RAAS inhibition reduced atrial fibrillation prevalence after cardiac surgery, spironolactone was protective against AKI while failing to decrease atrial fibrillation ${ }^{161}$.

\section{* Critically ill patients}


The ongoing trial "Usefulness of Spironolactone for the Prevention of Acute Kidney Injury in Critically Ill Patients with Invasive Mechanical Ventilation (NCT03206658)" was designed to evaluate the effect of spironolactone administration on the incidence and severity of AKI in critically ill patients with invasive mechanical ventilation in the critical care unit. Patients receive the medication during the first five days of stay in the critical care unit. The primary outcome is the level of urinary biomarkers of AKI (concentrations of NGAL, KIM-1, oxidative stress, and Hsp72 in urine). The "Spironolactone Administration to Prevent Ischemic Kidney Injury in Critically Ill Cancer Patients (SPIROCAN) (NCT02531412)" study aims to evaluate the impact of short-term spironolactone administration on the prevention of AKI among patients admitted to the intensive care unit in the immediate postoperative period (first 24 hours) following major surgery.

\section{* Coronary angiography/contrast-induced nephropathy}

In the RCT "Effect of Spironolactone on Acute Kidney Injury in Patients Undergoing Coronary Angiography (NCT03329443), ${ }^{162}$ patients will receive either spironolactone 200 mg single dose or placebo in addition to their usual premedication. The primary end point will be CIN, defined as a more than $25 \%$ or $0.3 \mathrm{mg} / \mathrm{dl}$ elevation in the level of serum creatinine from baseline during the first two to three days after the procedure.

\section{Clinical data: Benefit/risk over other therapies}

\section{MRAs as an adjunct therapy}

From a pathophysiological point of view, the phenomenon called "aldosterone breakthrough" favors the combinations MRA+ACEi or MRA+ARB. Indeed, RAS blockers initially decrease the plasma level of aldosterone, but this phenomenon is not sustained 
after long-term administration in 10 to $53 \%$ of patients, depending on the definition. ${ }^{163}$ Aldosterone levels may later reach or sometimes exceed pretreatment values. "Aldosterone breakthrough" limits the clinical efficacy of ACEis and ARBs, as it is associated with a poorer antiproteinuric response in patients with diabetic nephropathy. ${ }^{164}$ It was reported that aldosterone breakthrough is associated with an enhanced decline in GFR in patients with type 1 diabetes and diabetic nephropathy on long-term ARB treatment. ${ }^{165}$ This may be related to the direct deleterious effect of aldosterone. Nevertheless, in a post-hoc analysis of the AMADEO study, ${ }^{166}$ conducted among type 2 diabetic patients, the authors did not observe an association between aldosterone breakthrough at six months and the decline of the GFR between six months and one year. ${ }^{167}$ In this study, aldosterone breakthrough was defined as an increase of serum aldosterone levels $>10 \%$ over baseline values at six and 12 months of follow-up. The incidence of aldosterone breakthrough was $28 \%$ at one year. Aldosterone breakthrough at six months was not sustained at one year for $69 \%$ of cases.

In CKD, all available studies evaluated the effect of adding an MRA to an ACEi and/or ARB, RAS blockade being the gold-standard treatment of hypertension or proteinuria in these patients. There have been no placebo-controlled studies on MRAs without RAS blockers for the prevention of CKD progression. Moreover, there is no headto-head comparison of the efficacy of ACEis or ARBs with MRAs in CKD.

A RCT compared the combination of spironolactone/ARB vs ACEi/ARB in patients with DN. ${ }^{168}$ ACEi was discontinued in half of the patients with dual blockade (ACEi/ARB) of RAS and spironolactone was started after two weeks of washout. Patients receiving spironolactone and ARB showed a greater reduction of proteinuria after 18 months than those receiving ARB and ACEi. The eGFR declined significantly in both groups during follow-up and the decline rate did not differ significantly between the two. 
Clinical data thus support the interest of MRAs as an add-on therapy among patients with CKD to reduce proteinuria and optimize blood pressure control.

\section{Clinical data: Risk of hyperkalemia with MRAs in CKD}

Despite international guidelines, MRAs are still under-prescribed in the field of heart failure ${ }^{140,169}$ and resistant hypertension. ${ }^{170}$ Physicians are still reluctant to prescribe MRAs because of the risk of hyperkalemia and worsening renal function. ${ }^{169}$

* Risk of hyperkalemia in CKD patients

In the meta-analysis of Currie et al. (16 trials; $n=1356)$ evaluating the impact of the addition of MRA to ACEi and/ARB among CKD patients, the mean increase of potassium from baseline to end of trial only was $0.19 \mathrm{mmol} / \mathrm{L}, 95 \%$ CI $[0.12-0.27] .{ }^{127}$ Of note, the authors reported no effect of the baseline level of creatinine on the increase of potassium or the risk of hyperkalemia. Nevertheless, in these studies, the relative risk of hyperkalemia (whom threshold is varying according to the studies) was 3.02, $95 \%$ CI [1.75-5.18], and the relative risk of being withdrawn from active treatment due to MRA induced hyperkalemia was $3.21,95 \%$ CI $[1.19,8.71]$.

In the meta-analysis from Bolignano et al., similar results were found. ${ }^{126}$ Spironolactone in combination with ACEi and/or ARB increased the risk of hyperkalemia in CKD patients $(\mathrm{RR}=2.00,95 \% \mathrm{CI}[1.25-3.20])$ compared to ACEi and/or ARB (11 trials, $\mathrm{n}=632)$. The risk of hyperkalaemia also increased when spironolactone was used in addition to either an ACEi or ARB compared to ACEi or ARB alone (9 trials, $n=483$ ): RR 1.80, 95\% CI [1.09 to 2.96]. Spironolactone combined with ACEi and/or ARB increased serum potassium (mean difference $0.26 \mathrm{mmol} / \mathrm{L}, 95 \%$ CI [0.13-0.39]). 
The results of the meta-analyses should be interpreted with caution, given the heterogeneity of the included studies concerning: 1) the threshold of baseline serum potassium levels as an exclusion criterion, 2) the definition of hyperkalemia during followup, 3) the predefined procedures in case of hyperkalemia, including MRA dose reduction or withdrawal from active treatment. Importantly, patients with a theoretical indication of a MRA (heart failure, CKD) generally have an increased risk of hyperkalemia independent of the prescription of the MRA and some observed hyperkalemia events may not be related to the treatment. ${ }^{171}$ It is therefore necessary to interpret the frequency of hyperkalemia in RCTs relative to the placebo group. ${ }^{172}$ Nevertheless, dedicated studies are needed to precisely evaluate the long-term risk/benefit balance of MRAs in the setting of CKD.

\section{* Risk of hyperkalemia in patients on dialysis}

In the meta-analysis of nine trials (829 patients) published between 2005 and $2015^{153}$, the RR for hyperkalemia among patients in dialysis for MRA treatment was 3.05 (95\% CI, 1.21-7.70). However, the broad range of spironolactone doses used in the included studies (from $25 \mathrm{mg}$ every other day to $50 \mathrm{mg}$ twice a day) and the varying threshold of baseline serum potassium levels as exclusion criteria make it difficult to draw definitive conclusions concerning the safety of MRA for patients on dialysis. The ongoing ALCHEMIST RCT (NCT01848639) will be highly informative concerning the safety profile of long-term MRA administration among patients on hemodialysis. It is planned that the patients will receive up to $25 \mathrm{mg} /$ day spironolactone or placebo for two years. The primary outcome is the time to onset of the first incident, including non-fatal myocardial infarction, acute coronary syndrome, hospitalization for heart failure, nonfatal stroke, or 
$\mathrm{CV}$ death. The investigators plan to randomize 825 participants in this large multicenter RCT.

* Risk of hyperkalemia among kidney transplant recipients

Gonzales Monte et al. reported a good safety profile for the addition of spironolactone $25 \mathrm{mg}$ /day to ACEis and ARBs among 11 kidney transplant recipients with a baseline eGFR of $52 \pm 12.7 \mathrm{~mL} / \mathrm{min} .{ }^{173}$ After six months under MRA therapy, they reported a slight increase in serum potassium levels $(4.6 \pm 0.4 v s 5 \pm 0.62 \mathrm{mmol} / \mathrm{L})$, with no case of severe hyperkalemia. There was no MRA discontinuation during the study. Bertocchio et al. reported a good safety profile for the administration of eplerenone $25 \mathrm{mg} /$ day for two months among 31 kidney transplant recipients with moderate graft impairment (eGFR 30 to $50 \mathrm{~mL} / \mathrm{min}) .{ }^{174}$ Mild hyperkalemia (> $5 \mathrm{mmol} / \mathrm{L}$ ) was reported in less than $25 \%$ of patients and only one patient experienced moderate hyperkalemia, defined as serum potassium $>5.5$ $\mathrm{mmol} / \mathrm{L}$. There was no severe hyperkalemia (> $6 \mathrm{mmol} / \mathrm{L}$ ) during follow-up. The ongoing SPIREN RCT will be highly informative concerning the safety profile of long-term MRA administration among kidney transplant recipients, with the patients planned to receive spironolactone $25-50 \mathrm{mg} /$ day or placebo for three years. ${ }^{159}$

It is also important to analyze the risk of hyperkalemia from observational retrospective data, which may reflect "real life" more accurately than RCTs. An observational study included all citizens of Stockholm initiating MRA therapy from 2007 to $2010(n=13,726)$, with the identification of hyperkalemia events $(>5 \mathrm{mmol} / \mathrm{L})$ from all potassium measurements in healthcare. ${ }^{175}$ Overall, $18.5 \%$ of patients experienced at least one episode of hyperkalemia within a year, most within the first three months of therapy. CKD, as well as other comorbidities, was associated with an increased risk of 
hyperkalemia. After an hyperkalemia event, 47\% discontinued MRA and 10\% reduced the prescribed dose. CKD patients had the highest risk of MRA discontinuation. ${ }^{175}$ Of note, there was no reintroduction of MRA during the subsequent year for $76 \%$ of the patients who discontinued MRA.${ }^{175}$

\section{* Prevention of hyperkalemia}

Close monitoring of serum potassium levels is required for patients under MRA treatment. A large retrospective cohort study conducted among Medicare patients with heart failure reported that the rate of appropriate monitoring of serum potassium levels was very low. ${ }^{176}$ Appropriate monitoring was conducted more frequently among CKD patients but was still low. ${ }^{176}$ Such non-appropriate serum potassium monitoring certainly contributes to adverse events because clinicians are unable to adjust their prescription according to laboratory findings. Prevention of hyperkalemia among patients under MRA treatment should include dietary counseling, the avoidance of co-administration of other medications that could potentially induce hyperkalemia, and the correction of metabolic acidosis. ${ }^{177}$ Treatment of hyperkalemia may include potassium-binding resins ${ }^{177}$, including the new binders patiromer ${ }^{178-180}$, or sodium zirconium cyclosilicate $(\mathrm{ZS}-9)^{180-182}$ that are now both approved in the EU and the FDA. Of note, the development of the new potassium binders offers now opportunities to conduct trials among patients with advanced CKD to test the efficacy of MRAs either on CKD progression or on CV morbi-mortality. ${ }^{183} 178$ Finally, the reduction of the MRA dose may be necessary. ${ }^{177}$ Nevertheless, dose reduction obviously exposes patients to reduced efficacy of the MRAs.

* Risk of hyperkalemia depending on the type of MRA 
The risk of hyperkalemia may decrease with the use of finerenone. This non-steroidal MRA has higher selectivity than spironolactone (first generation steroidal MRA) and stronger affinity for the MR than eplerenone (second generation steroidal MRA). ${ }^{184,185}$ Potential higher selectivity for non-distal tubule cell targets may lead to lower potassium reabsorption in the distal nephron and reduced risk of hyperkalemia, with higher efficacy in other cell types. The higher potency versus that of spironolactone and eplerenone may also allow dose reduction. The therapeutic index may therefore be better with finerenone than spironolactone or eplerenone. ${ }^{186,187}$

\section{Conclusion}

Pre-clinical evidence shows the potential of MR antagonism to treat or delay kidney disease due to various etiologies, including ischemic kidney disease, diabetic and hypertensive nephropathy, glomerulonephritis, and calcineurin inhibitor toxicity in the context of kidney transplant. Promising clinical evidence shows a benefit of MRAs in proteinuria reduction in CKD. Further and larger studies to investigate the effectiveness of steroidal and novel non-steroidal MR antagonists to maintain kidney health in several clinical settings are urgently needed. 


\section{Disclosure}

Frédéric Jaisser received grants from BAYER AG, and AztraZeneca. 


\section{References}

1. Jaisser F, Farman N. Emerging Roles of the Mineralocorticoid Receptor in Pathology: Toward New Paradigms in Clinical Pharmacology. Pharmacol Rev. 2016;68(1):49-75.

2. Taira M, Toba H, Murakami M, et al. Spironolactone exhibits direct renoprotective effects and inhibits renal renin-angiotensin-aldosterone system in diabetic rats. Eur $J$ Pharmacol. 2008;589(1-3):264-271.

3. Quinkler M, Zehnder D, Eardley KS, et al. Increased expression of mineralocorticoid effector mechanisms in kidney biopsies of patients with heavy proteinuria. Circulation. 2005;112(10):1435-1443.

4. Krug AW, Allenhofer L, Monticone R, et al. Elevated mineralocorticoid receptor activity in aged rat vascular smooth muscle cells promotes a proinflammatory phenotype via extracellular signal-regulated kinase 1/2 mitogen-activated protein kinase and epidermal growth factor receptor-dependent pathways. Hypertension. 2010;55(6):1476-1483.

5. DeLano FA, Schmid-Schonbein GW. Enhancement of glucocorticoid and mineralocorticoid receptor density in the microcirculation of the spontaneously hypertensive rat. Microcirculation. 2004;11(1):69-78.

6. Kolkhof P, Barfacker L. 30 YEARS OF THE MINERALOCORTICOID RECEPTOR: Mineralocorticoid receptor antagonists: 60 years of research and development. J Endocrinol. 2017;234(1):T125-T140.

7. Kolkhof P, Nowack C, Eitner F. Nonsteroidal antagonists of the mineralocorticoid receptor. Curr Opin Nephrol Hypertens. 2015;24(5):417-424.

8. Mejia-Vilet JM, Ramirez V, Cruz C, Uribe N, Gamba G, Bobadilla NA. Renal ischemia-reperfusion injury is prevented by the mineralocorticoid receptor blocker spironolactone. Am J Physiol Renal Physiol. 2007;293(1):F78-86.

9. Ramirez V, Trujillo J, Valdes R, et al. Adrenalectomy prevents renal ischemiareperfusion injury. Am J Physiol Renal Physiol. 2009;297(4):F932-942.

10. Sanchez-Pozos K, Barrera-Chimal J, Garzon-Muvdi J, et al. Recovery from ischemic acute kidney injury by spironolactone administration. Nephrol Dial Transplant. 2012;27(8):3160-3169.

11. Barrera-Chimal J, Prince S, Fadel F, et al. Sulfenic Acid Modification of Endothelin B Receptor is Responsible for the Benefit of a Nonsteroidal Mineralocorticoid Receptor Antagonist in Renal Ischemia. J Am Soc Nephrol. 2016;27(2):398-404.

12. Lattenist L, Lechner SM, Messaoudi S, et al. Nonsteroidal Mineralocorticoid Receptor Antagonist Finerenone Protects Against Acute Kidney Injury-Mediated Chronic Kidney Disease: Role of Oxidative Stress. Hypertension. 2017;69(5):870878.

13. Barrera-Chimal J, Andre-Gregoire G, Nguyen Dinh Cat A, et al. Benefit of Mineralocorticoid Receptor Antagonism in AKI: Role of Vascular Smooth Muscle Rac1. J Am Soc Nephrol. 2017;28(4):1216-1226.

14. Ozacmak HS, Ozacmak VH, Barut F, Arasli M, Ucan BH. Pretreatment with mineralocorticoid receptor blocker reduces intestinal injury induced by ischemia and reperfusion: involvement of inhibition of inflammatory response, oxidative stress, 
nuclear factor kappaB, and inducible nitric oxide synthase. $J$ Surg Res. 2014;191(2):350-361.

15. Oyamada N, Sone M, Miyashita K, et al. The role of mineralocorticoid receptor expression in brain remodeling after cerebral ischemia. Endocrinology. 2008;149(8):3764-3777.

16. Kang YM, Zhang ZH, Johnson RF, et al. Novel effect of mineralocorticoid receptor antagonism to reduce proinflammatory cytokines and hypothalamic activation in rats with ischemia-induced heart failure. Circ Res. 2006;99(7):758-766.

17. Fiorentino M, Grandaliano G, Gesualdo L, Castellano G. Acute Kidney Injury to Chronic Kidney Disease Transition. Contrib Nephrol. 2018;193:45-54.

18. Barrera-Chimal J, Perez-Villalva R, Rodriguez-Romo R, et al. Spironolactone prevents chronic kidney disease caused by ischemic acute kidney injury. Kidney Int . 2013;83(1):93-103.

19. Barrera-Chimal J, Rocha L, Amador-Martinez I, et al. Delayed spironolactone administration prevents the transition from acute kidney injury to chronic kidney disease through improving renal inflammation. Nephrol Dial Transplant. 2018.

20. Barrera-Chimal J, Perez-Villalva R, Ortega JA, et al. Mild ischemic injury leads to long-term alterations in the kidney: amelioration by spironolactone administration. Int J Biol Sci. 2015;11(8):892-900.

21. Frieler RA, Ray JJ, Meng $\mathrm{H}$, et al. Myeloid mineralocorticoid receptor during experimental ischemic stroke: effects of model and sex. J Am Heart Assoc. 2012;1(5):e002584.

22. Frieler RA, Meng H, Duan SZ, et al. Myeloid-specific deletion of the mineralocorticoid receptor reduces infarct volume and alters inflammation during cerebral ischemia. Stroke. 2011;42(1):179-185.

23. Rickard AJ, Morgan J, Tesch G, Funder JW, Fuller PJ, Young MJ. Deletion of mineralocorticoid receptors from macrophages protects against deoxycorticosterone/salt-induced cardiac fibrosis and increased blood pressure. Hypertension. 2009;54(3):537-543.

24. Shen JZ, Morgan J, Tesch GH, et al. Cardiac Tissue Injury and Remodeling Is Dependent Upon MR Regulation of Activation Pathways in Cardiac Tissue Macrophages. Endocrinology. 2016;157(8):3213-3223.

25. Usher MG, Duan SZ, Ivaschenko CY, et al. Myeloid mineralocorticoid receptor controls macrophage polarization and cardiovascular hypertrophy and remodeling in mice. J Clin Invest. 2010;120(9):3350-3364.

26. Li C, Zhang YY, Frieler RA, et al. Myeloid mineralocorticoid receptor deficiency inhibits aortic constriction-induced cardiac hypertrophy in mice. PLoS One. 2014;9(10):e110950.

27. Rafatian N, Westcott KV, White RA, Leenen FH. Cardiac macrophages and apoptosis after myocardial infarction: effects of central MR blockade. Am J Physiol Regul Integr Comp Physiol. 2014;307(7):R879-887.

28. Greene EL, Kren S, Hostetter TH. Role of aldosterone in the remnant kidney model in the rat. J Clin Invest. 1996;98(4):1063-1068.

29. Aldigier JC, Kanjanbuch T, Ma LJ, Brown NJ, Fogo AB. Regression of existing glomerulosclerosis by inhibition of aldosterone. $J$ Am Soc Nephrol. 2005;16(11):3306-3314. 
30. Fujihara CK, Kowala MC, Breyer MD, et al. A Novel Aldosterone Antagonist Limits Renal Injury in 5/6 Nephrectomy. Sci Rep. 2017;7(1):7899.

31. Nagase M, Shibata S, Yoshida S, Nagase T, Gotoda T, Fujita T. Podocyte injury underlies the glomerulopathy of Dahl salt-hypertensive rats and is reversed by aldosterone blocker. Hypertension. 2006;47(6):1084-1093.

32. Arai K, Tsuruoka H, Homma T. CS-3150, a novel non-steroidal mineralocorticoid receptor antagonist, prevents hypertension and cardiorenal injury in Dahl saltsensitive hypertensive rats. Eur J Pharmacol. 2015;769:266-273.

33. Shibata S, Nagase M, Yoshida S, et al. Modification of mineralocorticoid receptor function by Rac1 GTPase: implication in proteinuric kidney disease. Nat Med. 2008;14(12):1370-1376.

34. Asai M, Monkawa T, Marumo T, et al. Spironolactone in combination with cilazapril ameliorates proteinuria and renal interstitial fibrosis in rats with anti-Thy-1 irreversible nephritis. Hypertens Res. 2004;27(12):971-978.

35. Gullulu M, Akdag I, Kahvecioglu S, Filiz G, Savci V. Aldosterone blockage in proliferative glomerulonephritis prevents not only fibrosis, but proliferation as well. Ren Fail. 2006;28(6):509-514.

36. Qin D, Morita H, Inui K, Tayama H, Inoue Y, Yoshimura A. Aldosterone mediates glomerular inflammation in experimental mesangial proliferative glomerulonephritis. J Nephrol. 2013;26(1):199-206.

37. Zitt E, Eller K, Huber JM, et al. The selective mineralocorticoid receptor antagonist eplerenone is protective in mild anti-GBM glomeru-lonephritis. Int $J$ Clin Exp Pathol. 2011;4(6):606-615.

38. Huang LL, Nikolic-Paterson DJ, Han Y, et al. Myeloid mineralocorticoid receptor activation contributes to progressive kidney disease. $J$ Am Soc Nephrol. 2014;25(10):2231-2240.

39. Ma FY, Han Y, Nikolic-Paterson DJ, Kolkhof P, Tesch GH. Suppression of Rapidly Progressive Mouse Glomerulonephritis with the Non-Steroidal Mineralocorticoid Receptor Antagonist BR-4628. PLoS One. 2015;10(12):e0145666.

40. Rocha R, Chander PN, Zuckerman A, Stier CT, Jr. Role of aldosterone in renal vascular injury in stroke-prone hypertensive rats. Hypertension. 1999;33(1 Pt 2):232237.

41. Brown NJ, Nakamura S, Ma L, et al. Aldosterone modulates plasminogen activator inhibitor-1 and glomerulosclerosis in vivo. Kidney Int. 2000;58(3):1219-1227.

42. Zhou X, Ono H, Ono Y, Frohlich ED. Aldosterone antagonism ameliorates proteinuria and nephrosclerosis independent of glomerular dynamics in LNAME/SHR model. Am J Nephrol. 2004;24(2):242-249.

43. Ikeda H, Tsuruya K, Toyonaga J, et al. Spironolactone suppresses inflammation and prevents L-NAME-induced renal injury in rats. Kidney Int. 2009;75(2):147-155.

44. Blasi ER, Rocha R, Rudolph AE, Blomme EA, Polly ML, McMahon EG. Aldosterone/salt induces renal inflammation and fibrosis in hypertensive rats. Kidney Int. 2003;63(5):1791-1800.

45. Nariai T, Fujita K, Mori M, Katayama S, Hori S, Matsui K. Antihypertensive and cardiorenal protective effects of SM-368229, a novel mineralocorticoid receptor antagonist, in aldosterone/salt-treated rats. Pharmacology. 2012;89(1-2):44-52. 
46. Bamberg K, Johansson U, Edman K, et al. Preclinical pharmacology of AZD9977: A novel mineralocorticoid receptor modulator separating organ protection from effects on electrolyte excretion. PLoS One. 2018;13(2):e0193380.

47. Arai K, Morikawa Y, Ubukata N, Tsuruoka H, Homma T. CS-3150, a Novel Nonsteroidal Mineralocorticoid Receptor Antagonist, Shows Preventive and Therapeutic Effects On Renal Injury in Deoxycorticosterone Acetate/Salt-Induced Hypertensive Rats. J Pharmacol Exp Ther. 2016;358(3):548-557.

48. Lother A, Furst D, Bergemann S, et al. Deoxycorticosterone Acetate/Salt-Induced Cardiac But Not Renal Injury Is Mediated By Endothelial Mineralocorticoid Receptors Independently From Blood Pressure. Hypertension. 2016;67(1):130-138.

49. Trachtman H, Weiser AC, Valderrama E, Morgado M, Palmer LS. Prevention of renal fibrosis by spironolactone in mice with complete unilateral ureteral obstruction. J Urol. 2004;172(4 Pt 2):1590-1594.

50. Chen H, Sun F, Zhong X, Shao Y, Yoshimura A, Liu Y. Eplerenone-mediated aldosterone blockade prevents renal fibrosis by reducing renal inflammation, interstitial cell proliferation and oxidative stress. Kidney Blood Press Res. 2013;37(6):557-566.

51. Wang $\mathrm{CH}$, Wang Z, Liang LJ, et al. The Inhibitory Effect of Eplerenone on Cell Proliferation in the Contralateral Kidneys of Rats with Unilateral Ureteral Obstruction. Nephron. 2017;136(4):328-338.

52. Keri KC, Samji NS, Blumenthal S. Diabetic nephropathy: newer therapeutic perspectives. J Community Hosp Intern Med Perspect. 2018;8(4):200-207.

53. Fujisawa G, Okada K, Muto S, et al. Spironolactone prevents early renal injury in streptozotocin-induced diabetic rats. Kidney Int. 2004;66(4):1493-1502.

54. Guo C, Martinez-Vasquez D, Mendez GP, et al. Mineralocorticoid receptor antagonist reduces renal injury in rodent models of types 1 and 2 diabetes mellitus. Endocrinology. 2006;147(11):5363-5373.

55. Yuan J, Jia R, Bao Y. Beneficial effects of spironolactone on glomerular injury in streptozotocin-induced diabetic rats. J Renin Angiotensin Aldosterone Syst. 2007;8(3):118-126.

56. Banki NF, Ver A, Wagner LJ, et al. Aldosterone antagonists in monotherapy are protective against streptozotocin-induced diabetic nephropathy in rats. PLoS One. 2012;7(6):e39938.

57. Lian M, Hewitson TD, Wigg B, Samuel CS, Chow F, Becker GJ. Long-term mineralocorticoid receptor blockade ameliorates progression of experimental diabetic renal disease. Nephrol Dial Transplant. 2012;27(3):906-912.

58. Pessoa BS, Peixoto EB, Papadimitriou A, Lopes de Faria JM, Lopes de Faria JB. Spironolactone improves nephropathy by enhancing glucose-6-phosphate dehydrogenase activity and reducing oxidative stress in diabetic hypertensive rat. $J$ Renin Angiotensin Aldosterone Syst. 2012;13(1):56-66.

59. Zhou G, Johansson U, Peng XR, Bamberg K, Huang Y. An additive effect of eplerenone to ACE inhibitor on slowing the progression of diabetic nephropathy in the db/db mice. Am J Transl Res. 2016;8(3):1339-1354.

60. Han SY, Kim CH, Kim HS, et al. Spironolactone prevents diabetic nephropathy through an anti-inflammatory mechanism in type 2 diabetic rats. J Am Soc Nephrol. 2006;17(5):1362-1372. 
61. Kang YS, Ko GJ, Lee MH, et al. Effect of eplerenone, enalapril and their combination treatment on diabetic nephropathy in type II diabetic rats. Nephrol Dial Transplant. 2009;24(1):73-84.

62. Nishiyama A, Kobori H, Konishi Y, et al. Mineralocorticoid receptor blockade enhances the antiproteinuric effect of an angiotensin II blocker through inhibiting podocyte injury in type 2 diabetic rats. J Pharmacol Exp Ther. 2010;332(3):10721080.

63. Lachaux M, Barrera-Chimal J, Nicol L, et al. Short- and long-term administration of the non-steroidal mineralocorticoid receptor antagonist finerenone opposes metabolic syndrome-related cardio-renal dysfunction. Diabetes Obes Metab. 2018;20(10):23992407.

64. Nagase M, Matsui H, Shibata S, Gotoda T, Fujita T. Salt-induced nephropathy in obese spontaneously hypertensive rats via paradoxical activation of the mineralocorticoid receptor: role of oxidative stress. Hypertension. 2007;50(5):877883.

65. Tokuyama H, Wakino S, Hara Y, et al. Role of mineralocorticoid receptor/Rho/Rhokinase pathway in obesity-related renal injury. Int J Obes (Lond). 2012;36(8):10621071.

66. Yoshida S, Ishizawa $\mathrm{K}$, Ayuzawa N, et al. Local mineralocorticoid receptor activation and the role of Rac1 in obesity-related diabetic kidney disease. Nephron Exp Nephrol. 2014;126(1):16-24.

67. Bobadilla NA, Gamba G. New insights into the pathophysiology of cyclosporine nephrotoxicity: a role of aldosterone. Am J Physiol Renal Physiol. 2007;293(1):F2-9.

68. McAuley FT, Whiting PH, Thomson AW, Simpson JG. The influence of enalapril or spironolactone on experimental cyclosporin nephrotoxicity. Biochem Pharmacol. 1987;36(5):699-703.

69. Perez-Rojas JM, Derive S, Blanco JA, et al. Renocortical mRNA expression of vasoactive factors during spironolactone protective effect in chronic cyclosporine nephrotoxicity. Am J Physiol Renal Physiol. 2005;289(5):F1020-1030.

70. Nielsen FT, Jensen BL, Marcussen N, Skott O, Bie P. Inhibition of mineralocorticoid receptors with eplerenone alleviates short-term cyclosporin A nephrotoxicity in conscious rats. Nephrol Dial Transplant. 2008;23(9):2777-2783.

71. Amador CA, Bertocchio JP, Andre-Gregoire G, et al. Deletion of mineralocorticoid receptors in smooth muscle cells blunts renal vascular resistance following acute cyclosporine administration. Kidney Int. 2016;89(2):354-362.

72. Feria I, Pichardo I, Juarez P, et al. Therapeutic benefit of spironolactone in experimental chronic cyclosporine A nephrotoxicity. Kidney Int. 2003;63(1):43-52.

73. Nielsen FT, Jensen BL, Hansen PB, Marcussen N, Bie P. The mineralocorticoid receptor antagonist eplerenone reduces renal interstitial fibrosis after long-term cyclosporine treatment in rat: antagonizing cyclosporine nephrotoxicity. BMC Nephrol. 2013;14:42.

74. Perez-Rojas J, Blanco JA, Cruz C, et al. Mineralocorticoid receptor blockade confers renoprotection in preexisting chronic cyclosporine nephrotoxicity. Am J Physiol Renal Physiol. 2007;292(1):F131-139.

75. Waanders F, Rienstra H, Boer MW, et al. Spironolactone ameliorates transplant vasculopathy in renal chronic transplant dysfunction in rats. Am J Physiol Renal Physiol. 2009;296(5):F1072-1079. 
76. Lahmer T, Hermans R, Schmaderer C, et al. Mineralocorticoid receptor antagonism and aldosterone synthesis inhibition do not improve glomerulosclerosis and renal interstitial fibrosis in a model of chronic kidney allograft injury. Kidney Blood Press Res. 2012;35(6):561-567.

77. Michea L, Villagran A, Urzua A, et al. Mineralocorticoid receptor antagonism attenuates cardiac hypertrophy and prevents oxidative stress in uremic rats. Hypertension. 2008;52(2):295-300.

78. Bonnard B, Pieronne-Deperrois M, Djerada Z, et al. Mineralocorticoid receptor antagonism improves diastolic dysfunction in chronic kidney disease in mice. $J$ Mol Cell Cardiol. 2018;121:124-133.

79. Bostick B, Habibi J, DeMarco VG, et al. Mineralocorticoid receptor blockade prevents Western diet-induced diastolic dysfunction in female mice. Am J Physiol Heart Circ Physiol. 2015;308(9):H1126-1135.

80. Jia G, Habibi J, Aroor AR, et al. Endothelial Mineralocorticoid Receptor Mediates Diet-Induced Aortic Stiffness in Females. Circ Res. 2016;118(6):935-943.

81. Takata H, Takeda Y, Zhu A, et al. Protective effects of mineralocorticoid receptor blockade against neuropathy in experimental diabetic rats. Diabetes Obes Metab. 2012;14(2):155-162.

82. Schupp N, Kolkhof P, Queisser N, et al. Mineralocorticoid receptor-mediated DNA damage in kidneys of DOCA-salt hypertensive rats. FASEB J. 2011;25(3):968-978.

83. Shibata S, Nagase M, Yoshida S, Kawachi H, Fujita T. Podocyte as the target for aldosterone: roles of oxidative stress and Sgk1. Hypertension. 2007;49(2):355-364.

84. Nishiyama A, Yao L, Nagai Y, et al. Possible contributions of reactive oxygen species and mitogen-activated protein kinase to renal injury in aldosterone/saltinduced hypertensive rats. Hypertension. 2004;43(4):841-848.

85. Keidar S, Kaplan M, Pavlotzky E, et al. Aldosterone administration to mice stimulates macrophage NADPH oxidase and increases atherosclerosis development: a possible role for angiotensin-converting enzyme and the receptors for angiotensin II and aldosterone. Circulation. 2004;109(18):2213-2220.

86. Calo LA, Zaghetto F, Pagnin E, et al. Effect of aldosterone and glycyrrhetinic acid on the protein expression of PAI-1 and p22(phox) in human mononuclear leukocytes. $J$ Clin Endocrinol Metab. 2004;89(4):1973-1976.

87. Taye A, Morawietz H. Spironolactone inhibits NADPH oxidase-induced oxidative stress and enhances eNOS in human endothelial cells. Iran J Pharm Res. 2011;10(2):329-337.

88. Iwashima F, Yoshimoto T, Minami I, Sakurada M, Hirono Y, Hirata Y. Aldosterone induces superoxide generation via Rac1 activation in endothelial cells. Endocrinology. 2008;149(3):1009-1014.

89. Fiebeler A, Luft FC. The mineralocorticoid receptor and oxidative stress. Heart Fail Rev. 2005;10(1):47-52.

90. Callera GE, Touyz RM, Tostes RC, et al. Aldosterone activates vascular p38MAP kinase and NADPH oxidase via c-Src. Hypertension. 2005;45(4):773-779.

91. Min LJ, Mogi M, Iwanami J, et al. Cross-talk between aldosterone and angiotensin II in vascular smooth muscle cell senescence. Cardiovasc Res. 2007;76(3):506-516.

92. McCurley A, Pires PW, Bender SB, et al. Direct regulation of blood pressure by smooth muscle cell mineralocorticoid receptors. Nat Med. 2012;18(9):1429-1433. 
93. Leopold JA, Dam A, Maron BA, et al. Aldosterone impairs vascular reactivity by decreasing glucose-6-phosphate dehydrogenase activity. Nat Med. 2007;13(2):189197.

94. Maron BA, Zhang YY, White K, et al. Aldosterone inactivates the endothelin-B receptor via a cysteinyl thiol redox switch to decrease pulmonary endothelial nitric oxide levels and modulate pulmonary arterial hypertension. Circulation. 2012;126(8):963-974.

95. Miyata K, Rahman M, Shokoji $\mathrm{T}$, et al. Aldosterone stimulates reactive oxygen species production through activation of NADPH oxidase in rat mesangial cells. $J$ Am Soc Nephrol. 2005;16(10):2906-2912.

96. Mathew JT, Patni H, Chaudhary AN, et al. Aldosterone induces mesangial cell apoptosis both in vivo and in vitro. Am J Physiol Renal Physiol. 2008;295(1):F73-81.

97. Petramala L, Pignatelli P, Carnevale R, et al. Oxidative stress in patients affected by primary aldosteronism. J Hypertens. 2014;32(10):2022-2029; discussion 2029.

98. Ojeda-Cervantes M, Barrera-Chimal J, Alberu J, Perez-Villalva R, MoralesBuenrostro LE, Bobadilla NA. Mineralocorticoid receptor blockade reduced oxidative stress in renal transplant recipients: a double-blind, randomized pilot study. Am J Nephrol. 2013;37(5):481-490.

99. Takebayashi K, Matsumoto S, Aso Y, Inukai T. Aldosterone blockade attenuates urinary monocyte chemoattractant protein-1 and oxidative stress in patients with type 2 diabetes complicated by diabetic nephropathy. J Clin Endocrinol Metab. 2006;91(6):2214-2217.

100. Caprio M, Newfell BG, la Sala A, et al. Functional mineralocorticoid receptors in human vascular endothelial cells regulate intercellular adhesion molecule-1 expression and promote leukocyte adhesion. Circ Res. 2008;102(11):1359-1367.

101. Miura R, Nakamura K, Miura D, et al. Anti-inflammatory effect of spironolactone on human peripheral blood mononuclear cells. J Pharmacol Sci. 2006;101(3):256-259.

102. Montes-Cobos E, Schweingruber N, Li X, Fischer HJ, Reichardt HM, Luhder F. Deletion of the Mineralocorticoid Receptor in Myeloid Cells Attenuates Central Nervous System Autoimmunity. Front Immunol. 2017;8:1319.

103. Sun JY, Li C, Shen ZX, et al. Mineralocorticoid Receptor Deficiency in Macrophages Inhibits Neointimal Hyperplasia and Suppresses Macrophage Inflammation Through SGK1-AP1/NF-kappaB Pathways. Arterioscler Thromb Vasc Biol. 2016;36(5):874885.

104. Buonafine M, Martinez-Martinez E, Amador C, et al. Neutrophil GelatinaseAssociated Lipocalin from immune cells is mandatory for aldosterone-induced cardiac remodeling and inflammation. J Mol Cell Cardiol. 2018;115:32-38.

105. Sun XN, Li C, Liu Y, et al. T-Cell Mineralocorticoid Receptor Controls Blood Pressure by Regulating Interferon-Gamma. Circ Res. 2017;120(10):1584-1597.

106. Amador CA, Barrientos V, Pena J, et al. Spironolactone decreases DOCA-saltinduced organ damage by blocking the activation of $\mathrm{T}$ helper 17 and the downregulation of regulatory T lymphocytes. Hypertension. 2014;63(4):797-803.

107. Herrada AA, Contreras FJ, Marini NP, et al. Aldosterone promotes autoimmune damage by enhancing Th17-mediated immunity. J Immunol. 2010;184(1):191-202.

108. Sun Y, Zhang J, Zhang JQ, Ramires FJ. Local angiotensin II and transforming growth factor-beta1 in renal fibrosis of rats. Hypertension. 2000;35(5):1078-1084. 
109. Martin-Fernandez B, Rubio-Navarro A, Cortegano I, et al. Aldosterone Induces Renal Fibrosis and Inflammatory M1-Macrophage Subtype via Mineralocorticoid Receptor in Rats. PLoS One. 2016;11(1):e0145946.

110. Brilla CG, Zhou G, Matsubara L, Weber KT. Collagen metabolism in cultured adult rat cardiac fibroblasts: response to angiotensin II and aldosterone. J Mol Cell Cardiol. 1994;26(7):809-820.

111. Zhou G, Kandala JC, Tyagi SC, Katwa LC, Weber KT. Effects of angiotensin II and aldosterone on collagen gene expression and protein turnover in cardiac fibroblasts. Mol Cell Biochem. 1996;154(2):171-178.

112. Diah S, Zhang GX, Nagai Y, et al. Aldosterone induces myofibroblastic transdifferentiation and collagen gene expression through the Rho-kinase dependent signaling pathway in rat mesangial cells. Exp Cell Res. 2008;314(20):3654-3662.

113. Nagai Y, Miyata K, Sun GP, et al. Aldosterone stimulates collagen gene expression and synthesis via activation of ERK1/2 in rat renal fibroblasts. Hypertension. 2005;46(4):1039-1045.

114. Chen D, Chen Z, Park C, et al. Aldosterone stimulates fibronectin synthesis in renal fibroblasts through mineralocorticoid receptor-dependent and independent mechanisms. Gene. 2013;531(1):23-30.

115. Irita J, Okura T, Kurata M, Miyoshi K, Fukuoka T, Higaki J. Osteopontin in rat renal fibroblasts: functional properties and transcriptional regulation by aldosterone. Hypertension. 2008;51(2):507-513.

116. Irita J, Okura T, Manabe S, et al. Plasma osteopontin levels are higher in patients with primary aldosteronism than in patients with essential hypertension. Am J Hypertens. 2006;19(3):293-297.

117. Huang LL, Nikolic-Paterson DJ, Ma FY, Tesch GH. Aldosterone induces kidney fibroblast proliferation via activation of growth factor receptors and PI3K/MAPK signalling. Nephron Exp Nephrol. 2012;120(4):e115-122.

118. Galmiche G, Pizard A, Gueret A, et al. Smooth muscle cell mineralocorticoid receptors are mandatory for aldosterone-salt to induce vascular stiffness. Hypertension. 2014;63(3):520-526.

119. Calvier L, Miana M, Reboul P, et al. Galectin-3 mediates aldosterone-induced vascular fibrosis. Arterioscler Thromb Vasc Biol. 2013;33(1):67-75.

120. Pruthi D, McCurley A, Aronovitz M, Galayda C, Karumanchi SA, Jaffe IZ. Aldosterone promotes vascular remodeling by direct effects on smooth muscle cell mineralocorticoid receptors. Arterioscler Thromb Vasc Biol. 2014;34(2):355-364.

121. Tarjus A, Martinez-Martinez E, Amador C, et al. Neutrophil Gelatinase-Associated Lipocalin, a Novel Mineralocorticoid Biotarget, Mediates Vascular Profibrotic Effects of Mineralocorticoids. Hypertension. 2015;66(1):158-166.

122. Martinez-Martinez E, Buonafine M, Boukhalfa I, et al. Aldosterone Target NGAL (Neutrophil Gelatinase-Associated Lipocalin) Is Involved in Cardiac Remodeling After Myocardial Infarction Through NFkappaB Pathway. Hypertension. 2017;70(6):1148-1156.

123. Calvier L, Martinez-Martinez E, Miana M, et al. The impact of galectin-3 inhibition on aldosterone-induced cardiac and renal injuries. JACC Heart Fail. 2015;3(1):59-67.

124. Artunc F, Lang F. Mineralocorticoid and SGK1-sensitive inflammation and tissue fibrosis. Nephron Physiol. 2014;128(1-2):35-39. 
125. Krug AW, Grossmann C, Schuster C, et al. Aldosterone stimulates epidermal growth factor receptor expression. J Biol Chem. 2003;278(44):43060-43066.

126. Bolignano D, Palmer SC, Navaneethan SD, Strippoli GF. Aldosterone antagonists for preventing the progression of chronic kidney disease. Cochrane Database Syst Rev. 2014(4):CD007004.

127. Currie G, Taylor AH, Fujita T, et al. Effect of mineralocorticoid receptor antagonists on proteinuria and progression of chronic kidney disease: a systematic review and meta-analysis. BMC Nephrol. 2016;17(1):127.

128. Hou J, Xiong W, Cao L, Wen X, Li A. Spironolactone Add-on for Preventing or Slowing the Progression of Diabetic Nephropathy: A Meta-analysis. Clin Ther. 2015;37(9):2086-2103 e2010.

129. Bakris GL, Agarwal R, Chan JC, et al. Effect of Finerenone on Albuminuria in Patients With Diabetic Nephropathy: A Randomized Clinical Trial. JAMA. 2015;314(9):884-894.

130. Bianchi S, Bigazzi R, Campese VM. Long-term effects of spironolactone on proteinuria and kidney function in patients with chronic kidney disease. Kidney Int. 2006;70(12):2116-2123.

131. Boesby L, Elung-Jensen T, Klausen TW, Strandgaard S, Kamper AL. Moderate antiproteinuric effect of add-on aldosterone blockade with eplerenone in non-diabetic chronic kidney disease. A randomized cross-over study. PLoS One. 2011;6(11):e26904.

132. Heerspink HJ, Kropelin TF, Hoekman J, de Zeeuw D. Drug-Induced Reduction in Albuminuria Is Associated with Subsequent Renoprotection: A Meta-Analysis. $J$ Am Soc Nephrol. 2015;26(8):2055-2064.

133. Avasare RS, Radhakrishnan J. Proteinuria as a surrogate marker for renal outcome: are we there yet? Kidney Int. 2015;88(6):1228-1230.

134. Levey AS, Cattran D, Friedman A, et al. Proteinuria as a surrogate outcome in CKD: report of a scientific workshop sponsored by the National Kidney Foundation and the US Food and Drug Administration. Am J Kidney Dis. 2009;54(2):205-226.

135. Table of Surrogate Endpoints That Were the Basis of Drug Approval or Licensure ; available https://www.fda.gov/Drugs/DevelopmentApprovalProcess/DevelopmentResources/uc m613636.htm.

136. Roy-Chaudhury P. Exploring Novel Endpoints for Clinical Trials in Kidney Disease: Challenges and Opportunities. Kidney Int Rep. 2017;2(3):295-296.

137. Strippoli GF, Craig JC, Schena FP. The number, quality, and coverage of randomized controlled trials in nephrology. J Am Soc Nephrol. 2004;15(2):411-419.

138. Levey AS, Inker LA, Matsushita K, et al. GFR decline as an end point for clinical trials in CKD: a scientific workshop sponsored by the National Kidney Foundation and the US Food and Drug Administration. Am J Kidney Dis. 2014;64(6):821-835.

139. Zannad F, Gattis Stough W, Rossignol P, et al. Mineralocorticoid receptor antagonists for heart failure with reduced ejection fraction: integrating evidence into clinical practice. Eur Heart J. 2012;33(22):2782-2795.

140. Ponikowski P, Voors AA, Anker SD, et al. 2016 ESC Guidelines for the diagnosis and treatment of acute and chronic heart failure: The Task Force for the diagnosis and treatment of acute and chronic heart failure of the European Society of Cardiology 
(ESC)Developed with the special contribution of the Heart Failure Association (HFA) of the ESC. Eur Heart J. 2016;37(27):2129-2200.

141. Girerd N, Ferreira JP, Rossignol P, Zannad F. A tentative interpretation of the TOPCAT trial based on randomized evidence from the brain natriuretic peptide stratum analysis. Eur J Heart Fail. 2016;18(12):1411-1414.

142. Eschalier R, McMurray JJ, Swedberg K, et al. Safety and efficacy of eplerenone in patients at high risk for hyperkalemia and/or worsening renal function: analyses of the EMPHASIS-HF study subgroups (Eplerenone in Mild Patients Hospitalization And SurvIval Study in Heart Failure). J Am Coll Cardiol. 2013;62(17):1585-1593.

143. Lofman I, Szummer K, Olsson H, Carrero JJ, Lund LH, Jernberg T. Association Between Mineralocorticoid Receptor Antagonist Use and Outcome in Myocardial Infarction Patients With Heart Failure. J Am Heart Assoc. 2018;7(14).

144. Pitt B, Kober L, Ponikowski P, et al. Safety and tolerability of the novel non-steroidal mineralocorticoid receptor antagonist BAY 94-8862 in patients with chronic heart failure and mild or moderate chronic kidney disease: a randomized, double-blind trial. Eur Heart J. 2013;34(31):2453-2463.

145. Edwards NC, Steeds RP, Stewart PM, Ferro CJ, Townend JN. Effect of spironolactone on left ventricular mass and aortic stiffness in early-stage chronic kidney disease: a randomized controlled trial. J Am Coll Cardiol. 2009;54(6):505512.

146. Edwards NC, Ferro CJ, Kirkwood H, et al. Effect of spironolactone on left ventricular systolic and diastolic function in patients with early stage chronic kidney disease. Am J Cardiol. 2010;106(10):1505-1511.

147. Boesby L, Elung-Jensen T, Strandgaard S, Kamper AL. Eplerenone attenuates pulse wave reflection in chronic kidney disease stage 3-4--a randomized controlled study. PLoS One. 2013;8(5):e64549.

148. DuPont JJ, Jaffe IZ. 30 YEARS OF THE MINERALOCORTICOID RECEPTOR: The role of the mineralocorticoid receptor in the vasculature. $J$ Endocrinol. 2017;234(1):T67-T82.

149. Taheri S, Mortazavi M, Shahidi S, et al. Spironolactone in chronic hemodialysis patients improves cardiac function. Saudi J Kidney Dis Transpl. 2009;20(3):392-397.

150. Taheri S, Mortazavi M, Pourmoghadas A, Seyrafian S, Alipour Z, Karimi S. A prospective double-blind randomized placebo-controlled clinical trial to evaluate the safety and efficacy of spironolactone in patients with advanced congestive heart failure on continuous ambulatory peritoneal dialysis. Saudi J Kidney Dis Transpl. 2012;23(3):507-512.

151. Sood MM, Pauly RP, Rigatto C, Komenda P. Left ventricular dysfunction in the haemodialysis population. NDT Plus. 2008;1(4):199-205.

152. Charytan DM, Himmelfarb J, Ikizler TA, et al. Safety and cardiovascular efficacy of spironolactone in dialysis-dependent ESRD (SPin-D): a randomized, placebocontrolled, multiple dosage trial. Kidney Int. 2018.

153. Quach K, Lvtvyn L, Baigent C, et al. The Safety and Efficacy of Mineralocorticoid Receptor Antagonists in Patients Who Require Dialysis: A Systematic Review and Meta-analysis. Am J Kidney Dis. 2016;68(4):591-598.

154. Hill NR, Lasserson D, Thompson B, et al. Benefits of Aldosterone Receptor Antagonism in Chronic Kidney Disease (BARACK D) trial-a multi-centre, prospective, randomised, open, blinded end-point, 36-month study of 2,616 patients 
within primary care with stage $3 \mathrm{~b}$ chronic kidney disease to compare the efficacy of spironolactone $25 \mathrm{mg}$ once daily in addition to routine care on mortality and cardiovascular outcomes versus routine care alone: study protocol for a randomized controlled trial. Trials. 2014;15:160.

155. Ng KP, Jain P, Heer G, et al. Spironolactone to prevent cardiovascular events in early-stage chronic kidney disease (STOP-CKD): study protocol for a randomized controlled pilot trial. Trials. 2014;15:158.

156. Ng KP, Jain P, Gill PS, et al. Results and lessons from the Spironolactone To Prevent Cardiovascular Events in Early Stage Chronic Kidney Disease (STOP-CKD) randomised controlled trial. BMJ Open. 2016;6(2):e010519.

157. Girerd S, Frimat L, Ducloux D, et al. EPURE Transplant (Eplerenone in Patients Undergoing Renal Transplant) study: study protocol for a randomized controlled trial. Trials. 2018;19(1):595.

158. Medeiros M, Velasquez-Jones L, Hernandez AM, et al. Randomized Controlled Trial of Mineralocorticoid Receptor Blockade in Children with Chronic Kidney Allograft Nephropathy. Clin J Am Soc Nephrol. 2017;12(8):1291-1300.

159. Mortensen LA, Thiesson HC, Tougaard B, Egfjord M, Fischer ASL, Bistrup C. The effect of spironolactone on calcineurin inhibitor induced nephrotoxicity: a multicenter randomized, double-blind, clinical trial (the SPIREN trial). BMC Nephrol. 2018;19(1):105.

160. Barba-Navarro R, Tapia-Silva M, Garza-Garcia C, et al. The Effect of Spironolactone on Acute Kidney Injury After Cardiac Surgery: A Randomized, Placebo-Controlled Trial. Am J Kidney Dis. 2017;69(2):192-199.

161. Pretorius M, Murray KT, Yu C, et al. Angiotensin-converting enzyme inhibition or mineralocorticoid receptor blockade do not affect prevalence of atrial fibrillation in patients undergoing cardiac surgery. Crit Care Med. 2012;40(10):2805-2812.

162. Mujtaba A, Taher MA, Hazza MA, et al. The Effect of Spironolactone on the Incidence of Contrast-Induced Nephropathy in Patients Undergoing Cardiac Catheterization: Study Design and Rationale. Cardiol Ther. 2018;7(1):101-106.

163. Bomback AS, Klemmer PJ. The incidence and implications of aldosterone breakthrough. Nat Clin Pract Nephrol. 2007;3(9):486-492.

164. Sato A, Hayashi K, Naruse M, Saruta T. Effectiveness of aldosterone blockade in patients with diabetic nephropathy. Hypertension. 2003;41(1):64-68.

165. Schjoedt KJ, Andersen S, Rossing P, Tarnow L, Parving HH. Aldosterone escape during blockade of the renin-angiotensin-aldosterone system in diabetic nephropathy is associated with enhanced decline in glomerular filtration rate. Diabetologia. 2004;47(11):1936-1939.

166. Bakris G, Burgess E, Weir M, Davidai G, Koval S, Investigators AS. Telmisartan is more effective than losartan in reducing proteinuria in patients with diabetic nephropathy. Kidney Int. 2008;74(3):364-369.

167. Moranne O, Bakris G, Fafin C, Favre G, Pradier C, Esnault VL. Determinants and changes associated with aldosterone breakthrough after angiotensin II receptor blockade in patients with type 2 diabetes with overt nephropathy. Clin J Am Soc Nephrol. 2013;8(10):1694-1701.

168. Esteghamati A, Noshad S, Jarrah S, Mousavizadeh M, Khoee SH, Nakhjavani M. Long-term effects of addition of mineralocorticoid receptor antagonist to angiotensin 
II receptor blocker in patients with diabetic nephropathy: a randomized clinical trial. Nephrol Dial Transplant. 2013;28(11):2823-2833.

169. Maggioni AP, Anker SD, Dahlstrom U, et al. Are hospitalized or ambulatory patients with heart failure treated in accordance with European Society of Cardiology guidelines? Evidence from 12,440 patients of the ESC Heart Failure Long-Term Registry. Eur J Heart Fail. 2013;15(10):1173-1184.

170. Williams B, Mancia G, Spiering W, et al. 2018 ESC/ESH Guidelines for the management of arterial hypertension. Eur Heart J. 2018.

171. Sarwar CM, Papadimitriou L, Pitt B, et al. Hyperkalemia in Heart Failure. J Am Coll Cardiol. 2016;68(14):1575-1589.

172. Vukadinovic D, Lavall D, Vukadinovic AN, Pitt B, Wagenpfeil S, Bohm M. True rate of mineralocorticoid receptor antagonists-related hyperkalemia in placebocontrolled trials: A meta-analysis. Am Heart J. 2017;188:99-108.

173. Gonzalez Monte E, Andres A, Polanco N, et al. Addition of spironolactone to dual blockade of renin angiotensin system dramatically reduces severe proteinuria in renal transplant patients: an uncontrolled pilot study at 6 months. Transplant Proc. 2010;42(8):2899-2901.

174. Bertocchio JP, Barbe C, Lavaud S, et al. Safety of Eplerenone for Kidney-Transplant Recipients with Impaired Renal Function and Receiving Cyclosporine A. PLoS One. 2016;11(4):e0153635.

175. Trevisan M, de Deco P, Xu H, et al. Incidence, predictors and clinical management of hyperkalaemia in new users of mineralocorticoid receptor antagonists. Eur J Heart Fail. 2018;20(8):1217-1226.

176. Cooper LB, Hammill BG, Peterson ED, et al. Characterization of Mineralocorticoid Receptor Antagonist Therapy Initiation in High-Risk Patients With Heart Failure. Circ Cardiovasc Qual Outcomes. 2017;10(1).

177. Roscioni SS, de Zeeuw D, Bakker SJ, Lambers Heerspink HJ. Management of hyperkalaemia consequent to mineralocorticoid-receptor antagonist therapy. Nat Rev Nephrol. 2012;8(12):691-699.

178. Weir MR, Bakris GL, Bushinsky DA, et al. Patiromer in patients with kidney disease and hyperkalemia receiving RAAS inhibitors. N Engl J Med. 2015;372(3):211-221.

179. Pitt B, Bakris GL, Weir MR, et al. Long-term effects of patiromer for hyperkalaemia treatment in patients with mild heart failure and diabetic nephropathy on angiotensinconverting enzymes/angiotensin receptor blockers: results from AMETHYST-DN. ESC Heart Fail. 2018;5(4):592-602.

180. Georgianos PI, Agarwal R. Revisiting RAAS blockade in CKD with newer potassium-binding drugs. Kidney Int. 2018;93(2):325-334.

181. Packham DK, Rasmussen HS, Lavin PT, et al. Sodium zirconium cyclosilicate in hyperkalemia. N Engl J Med. 2015;372(3):222-231.

182. Kosiborod M, Rasmussen HS, Lavin P, et al. Effect of sodium zirconium cyclosilicate on potassium lowering for 28 days among outpatients with hyperkalemia: the HARMONIZE randomized clinical trial. JAMA. 2014;312(21):2223-2233.

183. Pitt B, Bakris GL. New potassium binders for the treatment of hyperkalemia: current data and opportunities for the future. Hypertension. 2015;66(4):731-738. 
184. Kolkhof P, Delbeck M, Kretschmer A, et al. Finerenone, a novel selective nonsteroidal mineralocorticoid receptor antagonist protects from rat cardiorenal injury. J Cardiovasc Pharmacol. 2014;64(1):69-78.

185. Orena S, Maurer TS, She L, et al. PF-03882845, a non-steroidal mineralocorticoid receptor antagonist, prevents renal injury with reduced risk of hyperkalemia in an animal model of nephropathy. Front Pharmacol. 2013;4:115.

186. Liu LC, Schutte E, Gansevoort RT, van der Meer P, Voors AA. Finerenone : thirdgeneration mineralocorticoid receptor antagonist for the treatment of heart failure and diabetic kidney disease. Expert Opin Investig Drugs. 2015;24(8):1123-1135.

187. Kolkhof P, Jaisser F, Kim SY, Filippatos G, Nowack C, Pitt B. Steroidal and Novel Non-steroidal Mineralocorticoid Receptor Antagonists in Heart Failure and Cardiorenal Diseases: Comparison at Bench and Bedside. Handb Exp Pharmacol. 2017;243:271-305.

188. Nishiyama A, Yao L, Fan Y, et al. Involvement of aldosterone and mineralocorticoid receptors in rat mesangial cell proliferation and deformability. Hypertension. 2005;45(4):710-716.

189. Armanini D, Endres S, Kuhnle U, Weber PC. Parallel determination of mineralocorticoid and glucocorticoid receptors in T- and B-lymphocytes of human spleen. Acta Endocrinol (Copenh). 1988;118(4):479-482.

190. Ackermann D, Gresko N, Carrel M, et al. In vivo nuclear translocation of mineralocorticoid and glucocorticoid receptors in rat kidney: differential effect of corticosteroids along the distal tubule. Am $J$ Physiol Renal Physiol. 2010;299(6):F1473-1485.

191. Nguyen Dinh Cat A, Griol-Charhbili V, Loufrani L, et al. The endothelial mineralocorticoid receptor regulates vasoconstrictor tone and blood pressure. FASEB J. 2010;24(7):2454-2463.

192. Jaffe IZ, Mendelsohn ME. Angiotensin II and aldosterone regulate gene transcription via functional mineralocortocoid receptors in human coronary artery smooth muscle cells. Circ Res. 2005;96(6):643-650.

193. Terada Y, Kobayashi T, Kuwana H, et al. Aldosterone stimulates proliferation of mesangial cells by activating mitogen-activated protein kinase $1 / 2$, cyclin D1, and cyclin A. J Am Soc Nephrol. 2005;16(8):2296-2305.

194. Lim HY, Muller N, Herold MJ, van den Brandt J, Reichardt HM. Glucocorticoids exert opposing effects on macrophage function dependent on their concentration. Immunology. 2007;122(1):47-53.

195. Gilmour JS, Coutinho AE, Cailhier JF, et al. Local amplification of glucocorticoids by 11 beta-hydroxysteroid dehydrogenase type 1 promotes macrophage phagocytosis of apoptotic leukocytes. J Immunol. 2006;176(12):7605-7611.

196. Cole TJ, Young MJ. 30 YEARS OF THE MINERALOCORTICOID RECEPTOR: Mineralocorticoid receptor null mice: informing cell-type-specific roles. $J$ Endocrinol. 2017;234(1):T83-T92. 


\section{Author contributions}

JBC, SG, and FJ wrote the review.

\section{Acknowledgements}

This work was supported by grants from the Institut National de la Santé et de la Recherche Médicale, the Centre de Recherche Industrielle et Technique, the Agence Nationale de la Recherche (ANR-16-CE14-0021-01), the Fight-HF Avenir investment program (ANR-15RHUS-0004), the French Medical Research Foundation (DEQ20160334885), the FP7funded COST ADMIRE network (BM1301), the National Autonomous University of Mexico - DGAPA - PAPIIT (IA200117 and IN202919 to JBC), a public grant overseen by the French National Research Agency (ANR) as part of the second "Investissements d'Avenir" program (reference: ANR-15-RHU-0004), and GEENAGE Impact Lorraine Université d'Excellence- reference ANR-15-IDEX-04-LUE). 


\section{Tables}

\begin{tabular}{|c|c|c|c|c|c|c|c|c|}
\hline & $\begin{array}{c}\text { Distal } \\
\text { nephron }\end{array}$ & $\begin{array}{l}\text { Endothelial } \\
\text { cells }\end{array}$ & $\begin{array}{c}\text { Smooth } \\
\text { muscle cells }\end{array}$ & Podocytes & $\begin{array}{l}\text { Mesangial } \\
\text { cells }\end{array}$ & Fibroblasts & Macrophages & $\mathbf{T}$ cells \\
\hline $\begin{array}{l}\text { MR protein } \\
\text { expression }\end{array}$ & Yes $^{1}$ & Yes $^{1,100}$ & Yes $^{1}$ & Yes $^{138}$ & $\begin{array}{c}\text { Yes, } \\
\text { primary } \\
\text { culture }^{188}\end{array}$ & $\begin{array}{c}\text { Yes, cell } \\
\text { line, NRK- } \\
\text { 49F, rat }{ }^{113}\end{array}$ & $\begin{array}{c}\text { Yes bone } \\
\text { marrow } \\
\text { derived }^{23,25}\end{array}$ & $\begin{array}{c}\text { Yes } \\
\text { Isolated T } \\
\text { cells }^{105189}\end{array}$ \\
\hline $\begin{array}{c}\text { Prescence of } 11 \beta- \\
\text { hydroxysteroid } \\
\text { dehydrogenase type } 2\end{array}$ & Yes $^{190}$ & Yes ${ }^{100,191}$ & $\underset{192}{\text { Controversial }}$ & No & $\begin{array}{c}\text { Yes (In } \\
\text { vitro) })^{193}\end{array}$ & No & $\mathrm{No}^{194} 195$ & ND \\
\hline $\begin{array}{c}\text { Aldosterone effects in } \\
\text { vitro }\end{array}$ & Yes $^{1}$ & $\begin{array}{c}\text { Yes } \\
93 \\
94 \\
87\end{array}$ & $\begin{array}{c}\text { Yes } \\
90\end{array}$ & $\mathrm{Yes}^{83}$ & $\begin{array}{c}\text { Yes } \\
95,96 \\
112\end{array}$ & $\begin{array}{c}\text { Yes } \\
110,111 \\
115\end{array}$ & $\begin{array}{c}\text { Yes } \\
86 \\
104\end{array}$ & ND \\
\hline KO mice available & Yes $^{196}$ & Yes $^{196}$ & Yes $^{196}$ & $\mathrm{Yes}^{38}$ & No & No & $\begin{array}{c}\text { Yes } \\
\text { (Myeloid) }^{196}\end{array}$ & Yes $^{105}$ \\
\hline
\end{tabular}

Table 1. Summary of cell types expressing the MR, 11ß-hydroxysteroid dehydrogenase type 2, presenting aldosterone effects and for which the $\mathrm{KO}$ mice is available. 


\begin{tabular}{|c|c|c|c|c|c|c|}
\hline Trial & $\begin{array}{c}\text { Drug name and } \\
\text { dosage }\end{array}$ & Inclusion criteria & Exclusion criteria & $\begin{array}{c}\text { Patient } \\
\text { numbers }\end{array}$ & Endpoints & Fol \\
\hline $\begin{array}{c}\text { BARACK D } \\
\text { ISRCTN44522369 }\end{array}$ & $\begin{array}{l}\text { Spironolactone } \\
25 \text { mg per day }\end{array}$ & $\begin{array}{l}-\quad \text { Aged } 18 \text { years or above } \\
\text { CKD stage } 3 \mathrm{~b} \\
\left(\text { eGFR } 30-44 \mathrm{~mL} / \mathrm{min} / 1.73 \mathrm{~m}^{2}\right)\end{array}$ & 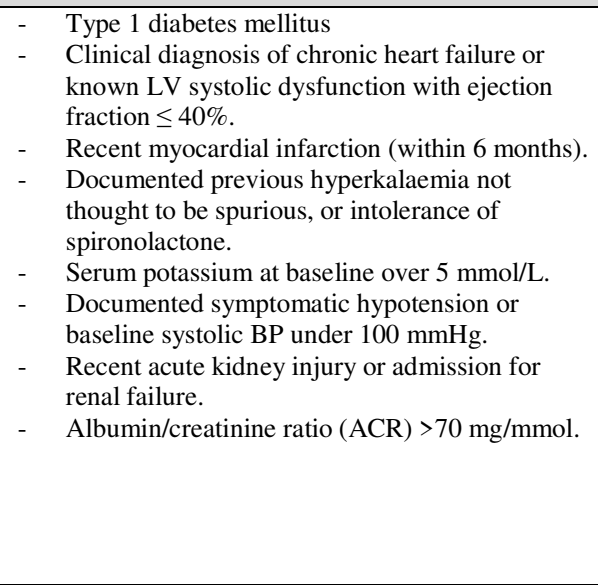 & $\begin{array}{l}2616(1,308 \\
\text { participants } \\
\text { per arm })\end{array}$ & $\begin{array}{l}\text { PRIMARY: Time from randomization until the } \\
\text { first occurring death, first onset, or hospitalisation } \\
\text { for heart disease (coronary heart disease, } \\
\text { arrhythmia, new onset/first recorded atrial } \\
\text { fibrillation, sudden death, failed sudden death), } \\
\text { stroke, or heart failure } \\
\text { SECONDARY: } \\
\text { - Change in BP annually and at final visit } \\
\text { - Rates of hypotension } \\
\text { - Changes in B-type natriuretic peptide (BNP) } \\
\text { - Change in urine ACR } \\
\text { - Changes in eGFR } \\
\text { - Change in health-related quality of life } \\
\text { - Incremental cost effectiveness analysis } \\
\text { - Transient ischaemic attack } \\
\text { - Rates of AEs } \\
\text { - Rates of hyperkalaemia }\end{array}$ & 36 months \\
\hline $\begin{array}{l}\text { ALCHEMIST } \\
\text { NCT01848639 }\end{array}$ & $\begin{array}{l}\text { Spironolactone } \\
\text { titrated over one } \\
\text { month to a } \\
\text { maximum single } \\
\text { dose of } 25 \mathrm{mg} / \mathrm{d}\end{array}$ & $\begin{array}{l}\text { - } \text { Aged } 18 \text { years or above } \\
\text { - On HD for at least } 45 \text { days for ESRD } \\
\text { regardless of the aetiology including } \\
\text { diabetes } \\
\text { - Presenting at least one of the follow } \\
\text { comorbidities, CV abnormalities or CV risk } \\
\text { factors: } \\
\text { - Left ventricular hypertrophy } \\
\text { OR left ventricular ejection fraction }<40 \% \\
\text { OR Left bundle branch block } \\
\text { Diabetes; } \\
\text { OR history of CV disease: coronary artery } \\
\text { disease, symptomatic lower limb peripheral } \\
\text { arterial disease, carotid or renal artery stenosis } \\
>50 \% \text {, stroke, hospitalization for heart } \\
\text { failure, permanent atrial fibrillation (AF), oral } \\
\text { anticoagulant treatment for AF, valvular heart } \\
\text { prosthesis, } \\
\text { OR CRP }>5 \mathrm{mg} / \mathrm{l} \text { for } 3 \text { months without } \\
\text { infectious or neoplastic disease }\end{array}$ & & $\begin{array}{l}825 \\
\text { participants }\end{array}$ & $\begin{array}{l}\text { PRIMARY: The time to onset of the first incident: } \\
\text { non-fatal MI or acute coronary syndrome or } \\
\text { hospitalization for heart failure or nonfatal stroke } \\
\text { or cardiovascular (CV) death } \\
\text { SECONDARY: } \\
\text { - The cumulate rate of non-fatal MI or acute } \\
\text { coronary syndrome, hospitalization for heart } \\
\text { failure, nonfatal stroke or CV death } \\
\text { - The time to onset of death from i) any cause and } \\
\text { ii) from a CV event and iii) from a non-CV cause } \\
\text { - The time of survival without a major CV event } \\
\text { (non-fatal MI, acute coronary syndrome, } \\
\text { hospitalization for heart failure, non-fatal stroke, } \\
\text { cardiac arrest resuscitation) } \\
\text { - Incidence of procedures related to stenosis or } \\
\text { vascular access thrombosis for hemodialysis (HD) } \\
\text { - Incidence of coronary or peripheral } \\
\text { revascularizations (including lower limb } \\
\text { amputations) } \\
\text { - BP and its inter visit variability } \\
\text { - The occurrence of AF } \\
\text { - Incidence of hyperkalemia> } 6 \text { mmol/l } \\
\text { - Estimation of the effect of treatment on quality of } \\
\text { life. }\end{array}$ & 24 months \\
\hline
\end{tabular}




\begin{tabular}{|c|c|c|c|c|c|c|}
\hline $\begin{array}{c}\text { FIGARO } \\
\text { NCT02545049 }\end{array}$ & $\begin{array}{l}\text { Finerenone } \\
10 \mathrm{mg} \text { or } 20 \mathrm{mg} \\
\text { once daily }\end{array}$ & $\begin{array}{ll}- & \text { Aged } 18 \text { years or above } \\
- & \text { Type } 2 \text { Diabetes Mellitus } \\
\text { - } & \text { Diagnosis of Diabetic Kidney Disease with } \\
\text { persistent high or very high albuminuria } \\
\text { - }\end{array}$ & $\begin{array}{l}\text { Hyperkalaemia }>5.5 \mathrm{mmol} / \mathrm{l} \text { during the two } \\
\text { weeks prior to enrolment } \\
\text { - History of unscheduled haemodialysis for } \\
\text { hyperkalaemia during the last six months } \\
\text { - Hospitalization for hyperkalaemia during the last } \\
\text { six months } \\
\text { - Patients with imperative indication of a } \\
\text { combination of ACEI and ARB or renin inhibitor } \\
\text { (each being authorized separately) }\end{array}$ & $\begin{array}{l}6400 \\
\text { participants }\end{array}$ & $\begin{array}{l}\text { PRIMARY: Time to the first occurrence of the } \\
\text { composite endpoint of CV death and non-fatal CV } \\
\text { events (myocardial infarction, stroke, or } \\
\text { hospitalization for heart failure) } \\
\text { SECONDARY: } \\
\text { - Time to first occurrence of the following } \\
\text { composite endpoints: onset of kidney failure, a } \\
\text { sustained decrease in estimated glomerular } \\
\text { filtration rate (eGFR) of } \geq 40 \% \text { from baseline } \\
\text { over at least } 4 \text { weeks and renal death } \\
\text { - Time to all-cause mortality } \\
\text { - Time to all-cause hospitalization } \\
\text { - Change in urinary albumin-to-creatine ratio } \\
\text { (UCAR) from baseline to month } 4 \\
\text { - Time to first occurrence of the following } \\
\text { composite endpoint: onset of kidney failure, a } \\
\text { sustained decrease in estimated glomerular } \\
\text { filtration rate (eGFR) of } \geq 57 \% \text { from baseline } \\
\text { over at least } 4 \text { weeks or renal death. }\end{array}$ & 53 months \\
\hline $\begin{array}{c}\text { FIDELIO } \\
\text { NCT02540993 }\end{array}$ & $\begin{array}{l}\text { Finerenone } 10 \\
\mathrm{mg} \text { or } 20 \mathrm{mg} \\
\text { once daily. }\end{array}$ & $\begin{array}{ll} & \text { Aged } 18 \text { years or above } \\
- & \text { Type } 2 \text { diabetes mellitus } \\
\text { - } & \text { Diagnosis of diabetic kidney disease } \\
\text { (DKD) with persistent high or very-high } \\
\text { albuminuria } \\
\text { - Pretreated with either ACEi or ARB at } \\
\text { maximal tolerated labelled dose without } \\
\text { adjustments } \\
\text { - } \\
\text { Serum potassium }<=4.8 \mathrm{mmol} / \mathrm{L} .\end{array}$ & $\begin{array}{l}\text { - Uncontrolled arterial hypertension } \\
\text { - Clinical diagnosis of chronic heart failure with } \\
\text { reduced ejection fraction (HFrEF) and persistent } \\
\text { symptoms New York Heart Association } \\
\text { (NYHA class II - IV) at run in visit (class 1A } \\
\text { recommendation for mineralocorticoid receptor } \\
\text { antagonist (MRAs) } \\
\text { - Dialysis for acute renal failure within } 12 \text { weeks } \\
\text { of run in visit } \\
\text { - Renal allograft in place or scheduled kidney } \\
\text { transplant within next } 12 \text { months } \\
\text { - Glycated haemoglobin HbA1c > } 12 \% \text {. }\end{array}$ & $\begin{array}{l}5734 \\
\text { participants }\end{array}$ & $\begin{array}{l}\text { PRIMARY: Time to the first occurrence of the } \\
\text { composite endpoint of onset of kidney failure, a } \\
\text { sustained decrease of eGFR } \geq 40 \% \text { from baseline } \\
\text { over at least } 4 \text { weeks and renal death. } \\
\text { SECONDARY: } \\
\text { - Time to first occurrence of the composite } \\
\text { endpoint: CV death or non-fatal CV events } \\
\text { (myocardial infarction, stroke, hospitalization } \\
\text { for heart failure) } \\
\text { - Time to all-cause mortality } \\
\text { - Time to all-cause hospitalizations } \\
\text { - Time to first occurrence of the following } \\
\text { composite endpoint: onset of kidney failure, a } \\
\text { sustained decrease in eGFR of } \geq 57 \% \text { from } \\
\text { baseline over at least } 4 \text { weeks or renal death. } \\
\text { - Change in urinary albumin-to-creatinine ratio } \\
\text { (UACR) from baseline to month } 4\end{array}$ & 48 months \\
\hline
\end{tabular}

Table 2. Ongoing clinical trials evaluating cardiovascular outcomes with MRAs among CKD patients. 